\title{
Calibration of QM-MOURA three-axis magnetometer and gradiometer
}

\author{
M. Díaz-Michelena ${ }^{1}$, R. Sanz ${ }^{1, *}$, M. F. Cerdán ${ }^{1,2}$, and A. B. Fernández ${ }^{1}$ \\ ${ }^{1}$ National Institute of Aerospace Technology, Ctra. de Ajalvir, km 4, 28850 Torrejón de Ardoz, Madrid, Spain \\ ${ }^{2}$ Departamento de Física de la Tierra, Astronomía y Astrofísica I, Universidad Complutense de Madrid, \\ Pza. de las Ciencias, s/n, 28040 Madrid, Spain \\ *now at: CNR-IMM MATIS at Dipartimento di Fisica e Astronomia, Università di Catania, Via S. Sofia 64, \\ 95123 Catania, Italy
}

Correspondence to: M. Díaz-Michelena (diazma@inta.es)

Received: 17 January 2014 - Published in Geosci. Instrum. Method. Data Syst. Discuss.: 4 August 2014

Revised: 22 December 2014 - Accepted: 5 January 2015 - Published: 30 January 2015

\begin{abstract}
MOURA instrument is a three-axis magnetometer and gradiometer designed and developed for Mars MetNet Precursor mission.

The initial scientific goal of the instrument is to measure the local magnetic field in the surroundings of the lander i.e. to characterize the magnetic environment generated by the remanent magnetization of the crust and the superimposed daily variations of the field produced either by the solar wind incidence or by the thermomagnetic variations. Therefore, the qualification model $(\mathrm{QM})$ will be tested in representative scenarios like magnetic surveys on terrestrial analogues of Mars and monitoring solar events, with the aim to achieve some experience prior to the arrival to Mars.

In this work, we present a practical first approach for calibration of the instrument in the laboratory; a finer correction after the comparison of MOURA data with those of a reference magnetometer located in San Pablo de los Montes (SPT) INTERMAGNET Observatory; and a comparative recording of a geomagnetic storm as a demonstration of the compliance of the instrument capabilities with the scientific objectives.
\end{abstract}

\section{Introduction}

MOURA is a three-axis magnetometer and gradiometer instrument, to be included in the Spanish payload for the Finnish-Russian-Spanish Mars MetNet Precursor Mission (MMPM, 2014), rescheduled for 2018. The mission concept of MMPM is to deploy the first lander of a net of meteorological stations based on the penetrator concept over the surface of Mars. One of the targeted measurements of MOURA instrument will be to measure the change in remanent magnetization of Mars lithospheric minerals. We will measure the thermoremanent behaviour of surface rocks and search for temperature transitions for the compositional analysis of the crust (Sanz et al., 2011; Fernández et al., 2013) aiming to explain its local magnetic anomalies, with intensities several orders of magnitude higher than the Earth ones. The second scientific objective is to measure the variations of the field related to the solar wind effects. The intensities corresponding to these magnetic fields are summarized in Table 1 for the Earth and Mars.

Due to the limited development time (2 years), mass and energy constraints of the mission $(150 \mathrm{~g}$ and $>0.5 \mathrm{~W}$ for the three Spanish payloads), and the Martian environment envelope (temperatures ranging from -90 to $20^{\circ} \mathrm{C}$ in operation and from -120 to $125^{\circ} \mathrm{C}$ storage, and a total irradiation dose up to $15 \mathrm{krad} \mathrm{Si}^{-1}$ ), MOURA development has singular characteristics, which have an impact on its performances. MOURA consists of a double design: one compact sensor with macroscopic front-end electronics including many COTS and PEMS components up-screened for the mission, and a second with a mixed applied specific integrated circuit (ASIC) based front-end (Sordo-Ibáñez et al., 2014). This work focuses on the former one. MOURA instrument is located on top of the inflatable structure of the lander (Fig. 1) to provide a certain distance from the penetrator, avoiding 
Table 1. Main field intensities of the magnetic sources on Earth and Mars.

\begin{tabular}{|c|c|c|c|c|}
\hline Source & Feature & Earth & $\begin{array}{l}\text { Mars } \\
\text { (estimated) }\end{array}$ & $\begin{array}{l}\text { Main temporal and } \\
\text { spatial characteristics }\end{array}$ \\
\hline Interior & Palaeodipole & $10^{22}-10^{23} \mathrm{Am}^{2}$ & $<2 \times 10^{18} \mathrm{Am}^{2}$ & Inversions \\
\hline Crust & $\begin{array}{l}\text { Strong, stable, } \\
\text { remanent } \\
\text { magnetization }\end{array}$ & $0.1-1 \mathrm{Am}^{-1}$ & $12-20 \mathrm{Am}^{-1}$ & $\begin{array}{l}\text { Tens of km thick } \\
\text { magnetized layer }\end{array}$ \\
\hline Surface & $\begin{array}{l}\text { Surface rocks } \\
\text { Local strong } \\
\text { magnetic fields }\end{array}$ & $\begin{array}{l}100 \mathrm{nT} \\
10-10^{4} \mathrm{nT}\end{array}$ & $\begin{array}{l}10^{5} \mathrm{nT} \\
2200 \mathrm{nT}\end{array}$ & $\begin{array}{l}\text { Earth: attributed to some } \\
\text { geological structures } \\
\text { (volcanoes, magnetite } \\
\text { outcrops ...) } \\
\text { Mars: mainly in the } \\
\text { highlands in the Southern } \\
\text { Hemisphere }\end{array}$ \\
\hline \multirow[t]{8}{*}{$\begin{array}{l}\text { Ionosphere } \\
\text { and } \\
\text { magnetosphere }\end{array}$} & Daily variation & $\begin{array}{l}20 \mathrm{nT}(200 \mathrm{nT} \\
\text { in the equator) }\end{array}$ & $\begin{array}{l}0.5-5 \mathrm{nT} \\
\text { in the } \\
\text { Equator }\end{array}$ & \\
\hline & $\begin{array}{l}\text { Sun storms/ } \\
\text { substorms }\end{array}$ & $100-1000 \mathrm{nT}$ & Few nT & $\begin{array}{l}\text { Earth aurora: Auroral oval } \\
\text { surface, } 80-500 \mathrm{~km} \\
\text { height } \\
\text { Mars aurora: } 30 \mathrm{~km} \text { long - } \\
8 \mathrm{~km} \text { height }\end{array}$ \\
\hline & $\begin{array}{l}\text { Elongated shape } \\
\text { density bulges near } \\
\text { the surface }\end{array}$ & - & Few nT & Local magnetospheres \\
\hline & Pulses & $0.1-100 \mathrm{nT}$ & - & \\
\hline & Flux ropes & $20 \mathrm{nT}$ & $<5 \mathrm{nT}$ & \\
\hline & $\begin{array}{l}\text { Interplanetary - } \\
\text { planetary transition }\end{array}$ & $30 \mathrm{nT}$ & $<5 \mathrm{nT}$ & $\begin{array}{l}\text { Earth: solar wind- } \\
\text { magnetosphere, Mars: } \\
\text { solar wind-ionosphere }\end{array}$ \\
\hline & Several layers & $\begin{array}{l}\approx 2500 \mathrm{nT} \\
(\mathrm{IGMR})\end{array}$ & Few nT & From 80 to $200 \mathrm{~km}$ height \\
\hline & Plasma current & $10-20 \mathrm{nT}$ & $<5 \mathrm{nT}$ & \\
\hline
\end{tabular}

any extra mass for a deployment system. Therefore, apart from the two magnetometers (for close gradiometry) and the compensating temperature sensors, it has a tilt angle detector to determine the relative position with respect to the horizontal.

Because of the above-mentioned mission constraints, both the sensing and the electronics suppose a trade-off between performances under the expected environment, power and mass budget. In addition, the magnetic signal of the electronic components was also carefully measured, in order to improve the magnetic cleanliness of the compact instrument. As a result, the parts list for the electronics was restricted according to their magnetic signal. Under the mentioned demanding criteria, the selected sensing element was the triaxial HMC1043 magnetic sensor by Honeywell (Honeywell Magnetic Sensors, 2014). The HMC1043 sensors belong to a family of sensors based on anisotropic magnetoresistance (AMR) effect (Freitas et al., 2007) which has been exhaus- tively up-screened (temperature, thermal shock, life cycle, and radiation) by INTA (Sanz et al., 2012) and successfully used in previous space missions (D. Michelena et al., 2010; D. Michelena, 2009; DTUsat, 2014). Although the selection of HMC1043 for the two magnetic sensing elements presents advantages in terms of weight and power consumption, the AMR technology based sensors present several drawbacks like their resolution (lower compared with other sensing technologies, like the fluxgates), or an important dependence of their response (gain and offset) with temperature (Ripka et al., 2013; Díaz-Michelena et al., 2014). This point is particularly challenging because MOURA is expected to be allocated outside the lander (Fig. 1) and thus be exposed to Mars surface thermal fluctuations. As one of the main objectives of MOURA is to measure the thermal variation of Martian magnetic minerals magnetization, this thermal characterization of the instrument becomes critical. Due to the necessities of the project, and after the successful qualification (mechan- 
Table 2. MOURA characteristics summary.

\begin{tabular}{|c|c|c|c|c|c|}
\hline Characteristics & Conditions & Min & Typical & Max & Unit \\
\hline Sourcing voltage $\left(V_{\mathrm{dd}}\right)$ & & 4.5 & 5 & 5.5 & $\mathrm{~V}$ \\
\hline Set/reset voltage $\left(V_{\mathrm{s} / \mathrm{r}}\right)$ & & 10 & 12 & 15 & $\mathrm{~V}$ \\
\hline Sourcing current $\left(I_{\mathrm{dd}}\right)$ & @ 5 V, RT, stand-by & 81 & & 86 & $\mathrm{~mA}$ \\
\hline Set/reset current $\left(I_{\mathrm{S} / \mathrm{r}}\right)$ & @ $12 \mathrm{~V}, \mathrm{RT}$ & & $<2$ & & $\mathrm{~mA}$ \\
\hline Operating temperature & & -100 & & 70 & ${ }^{\circ} \mathrm{C}$ \\
\hline Storage temperature & & -130 & & 125 & ${ }^{\circ} \mathrm{C}$ \\
\hline Field range & Nominal & & \pm 65 & & $\mu \mathrm{T}$ \\
\hline Extended range & Auto-offset compensation & & \pm 130 & & $\mu \mathrm{T}$ \\
\hline Linearity error & Nominal range & & $<0.5$ & & $\% \mathrm{FS}$ \\
\hline Hysteresis error & Nominal range & & $<0.1$ & & $\% \mathrm{FS}$ \\
\hline Repeatability error & Nominal range & & $<0.1$ & & $\% \mathrm{FS}$ \\
\hline Sensitivity & & & 0.45 & & Cts nT ${ }^{-1}$ \\
\hline Resolution & & & 2.2 & & $\mathrm{nT}$ \\
\hline \multirow[t]{3}{*}{ PSD } & $\begin{array}{l}@ 0.5 \mathrm{~Hz} \\
\text { samples averaged: } 1\end{array}$ & & 0.85 & & $\mathrm{nT} \sqrt{ } \mathrm{Hz}^{-1}$ \\
\hline & $\begin{array}{l}\text { @ } 0.5 \mathrm{~Hz} \\
\text { samples averaged: } 10\end{array}$ & & 0.42 & & $\mathrm{nT} \sqrt{ } \mathrm{Hz}^{-1}$ \\
\hline & $\begin{array}{l}\text { @ } 0.5 \mathrm{~Hz} \\
\text { samples averaged: } 100\end{array}$ & & 0.28 & & $\mathrm{nT} \sqrt{ } \mathrm{Hz}^{-1}$ \\
\hline Mass & & & 72 & & $\mathrm{~g}$ \\
\hline Box dimensions & & & $150 \times 30 x \times 15$ & & $\mathrm{~mm}$ \\
\hline
\end{tabular}

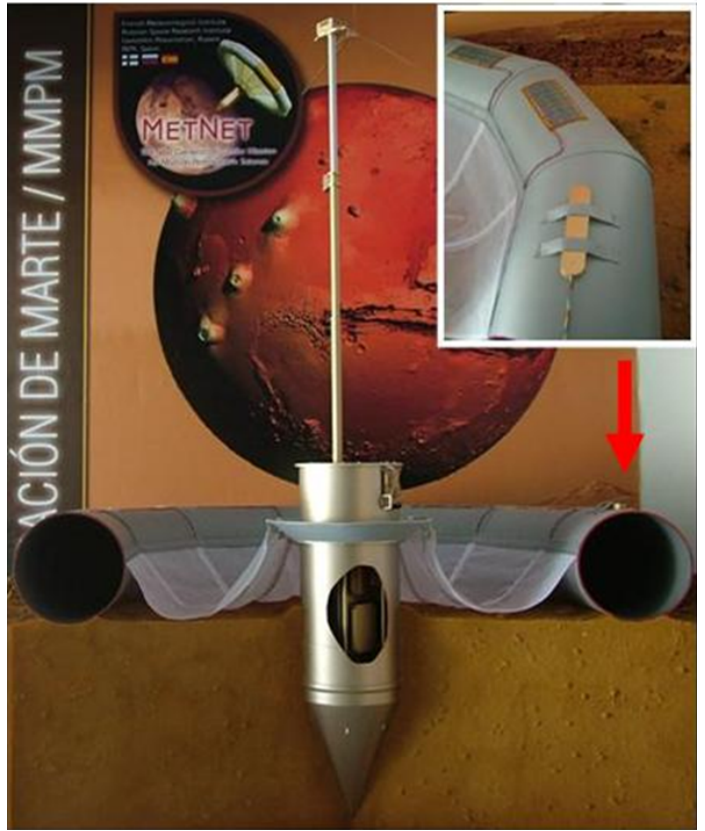

Figure 1. MMPM mock-up. The inset shows the position of MOURA sewn to the inflatable structure of the lander (red arrow).

ical shock, vibration, thermal and vacuum), the qualification model (QM) of the magnetometer was slightly modified, and therefore should be strictly denominated engineering qualification model (EQM). This EQM is still fully representative (electric and functional) of the flight model (FM) but not me- chanically representative. This fact will have implications in the calibration with temperature of the instrument.

In the present work we focus on the first calibrations performed to MOURA EQM (MOURA from now on) as is (Fig. 2), which involves: magnetic, tilt angle detector, including gravity measurements characterization, and thermal behaviours. The purpose of this calibration is to demonstrate the capability of MOURA instrument to fulfil the abovementioned scientific objectives on Mars by means of measurements on Earth. For this reason, the field range has been increased to $\pm 65000 \mathrm{nT}$ (extendable to $\pm 130000 \mathrm{nT}$, see Table 2).

On Earth the contrast in magnetic field intensity in onground prospections is generally due to the magnetic carriers of the surface rocks (up to tens of metres). Despite the limited data of ground surveys on Earth, a reasonable goal in terms of detectability for MOURA instrument is to be able to detect a variation of $1 \%$ vol. concentration of pyrrhotite by the corresponding magnetic contrast $(20 \mathrm{nT})$ apart from the daily variations corresponding to either the temperature swings and the solar wind incidence. Finally, to demonstrate experimentally the capability of the sensor, and for a fine recalibration, we show a comparison of the corrected data registered by MOURA versus the official magnetic daily variation data provided by San Pablo de los Montes Geomagnetic Observatory (IAGA code: SPT) (Geomagnetic observatories, 2014). 


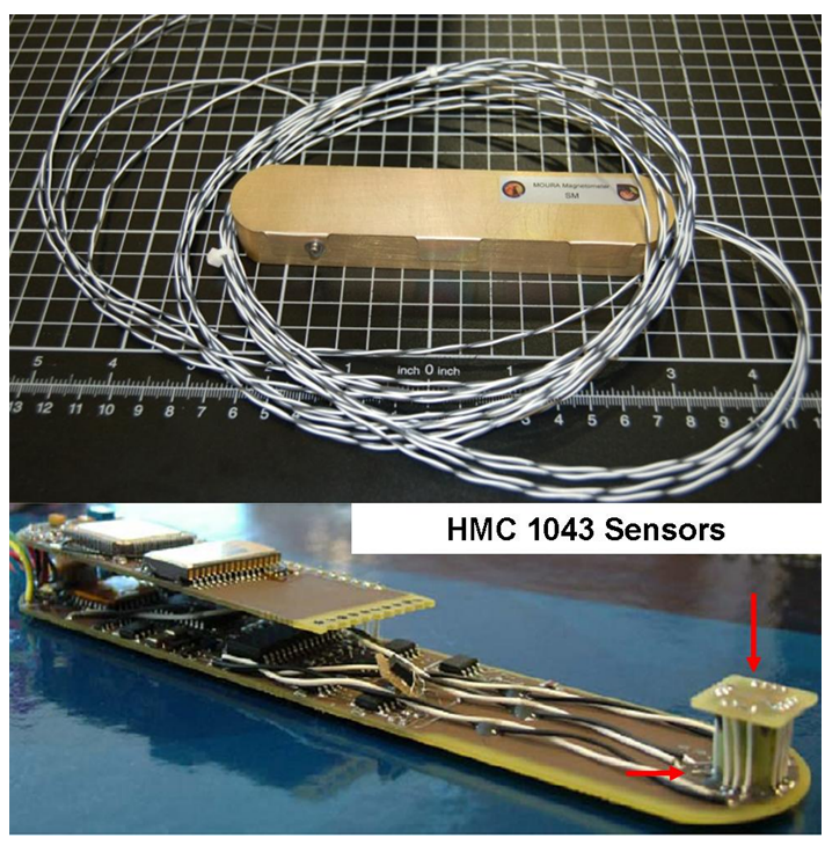

Figure 2. QM-MOURA box and detailed view of position of both HMC1043 sensors (red arrows).

\section{Devices and equipment}

In this section a brief description of the tested instrument and devices employed are presented.

\subsection{Brief description of MOURA and tested parameters}

MOURA is a vector magnetometer and gradiometer to measure the magnetic environment on the surface of Mars. It is based on AMR technology. The main characteristics of the instrument are summarized in Table 2.

The front-end is based on a flipping mode of the AMR, the SET/RESET flip recommended by the manufacturer (Honeywell Magnetic Sensors, 2014) in order to avoid crossaxis effects, increase repeatability by decreasing the thermal disorder of magnetic domains, and reduce hysteresis. Therefore, the measurement will consist in the subtraction of the two mirror states (after the SET and RESET pulses): Set-Reset mode (set pulse $-V_{\text {Set }}$ acquisition - reset pulse $-V_{\text {Reset }}$ acquisition - calculation of $\left.V_{\mathrm{S} / \mathrm{R}}=\left(V_{\mathrm{Set}}-V_{\mathrm{Reset}}\right) / 2 \ldots\right)$ with open loop conditioning of the AMR Wheatstone bridges, though either operations in set/reset (set/reset pulse $-V_{\text {Set/Reset }}-$ set/reset pulse $V_{\text {Set/Reset }} . .$. ) or just one pulse based modes (set/reset pulse $V_{\text {Set/Reset }}-V_{\text {Set/Reset }} \ldots$ ) are foreseen. In order to guarantee the correct flipping of the domains in the AMR, and therefore its repeatability, the pulses of SET and RESET are generated by the discharge of several capacitors charged to $12 \mathrm{~V}$. The shape of the pulses is therefore that of the capacitors' discharge.
The noise is expected to be of the order of $1 \mathrm{nT}$. The offset coils are used for the calibration of the sensor gain and to double the dynamic range (to $\pm 130000 \mathrm{nT}$ max.) when the response of any axis is saturated. Due to mass and power constraints, the instrument is designed to operate in open loop (no feedback) and the thermal compensation is performed by calibration in contrast to other developments (Brown et al., 2012; Ripka et al., 2013; Díaz Michelena et al., 2015). The consequent cross-axis effects will be assumed.

The instrument has several temperature sensors based on platinum resistors (PT-1000 previously calibrated) for the compensation of the thermal drifts of the different elements. Of particular importance are the temperature sensors located on top of the two magnetometers (TMP1 and TMP2), which will be used for the compensation of the magnetic signals with temperature.

The instrument also comprises a tilt angle detector (a three-axis accelerometer ADXL327 by Analog Devices) for the correction of the inclination and northing. The accelerometer is selected amongst other devices because of its lower magnetic signature (magnetic moment lower than $1 \mu \mathrm{Am}^{2}$ when exposed to moderate fields ( $100 \mathrm{pT}$ ) contributing less than $0.5 \mathrm{nT}$ in the position of the sensor).

The instrument has a physical envelope of $150 \times 30$ $\times 15 \mathrm{~mm}^{3}$ and a weight of $72 \mathrm{~g}$.

For the present characterization we focus on the signals described in Table 3 (denoted as channels).

\subsection{Equipment}

All the calibration has been performed in the Space Magnetism Laboratory at INTA headquarters with the exception of the magnetic daily variations, which were registered in San Pablo de los Montes Observatory, Toledo, Spain.

Controlled magnetic fields are generated by a set of three pairs of high mechanical precision Helmholtz coils (HC), model Ferronato BH300-A. Each pair of coils (denoted as $\mathrm{HC}_{X}, \mathrm{HC}_{Y}$ and $\left.\mathrm{HC}_{Z}\right)$ is calibrated by means of Bartington FG100 fluxgate (certified by Bartington, against the calibration references, in accordance with ISO10012: Mag-01 magnetometer, Mag Probe B, solenoid with current source and DC scaling solenoid, Table 4). The coil constants are: $\mathrm{HC}_{X}=524.38 \mathrm{p} \mathrm{TA}^{-1}, \mathrm{HC}_{Y}=542.15 \mathrm{p} \mathrm{TA}^{-1}$ and $\mathrm{HC}_{Z}=525.60 \mathrm{p} \mathrm{TA}^{-1}$. The electric currents to generate the magnetic fields are supplied by a Keithley 6220 precision current source.

Non-orthogonalities in the $\mathrm{HC}$ are lower than $4 "$; according to the documentation provided by the manufacturer (Honeywell Magnetic Sensors, 2014), orthogonality between $x-y$ axes is better than $3.6^{\prime \prime}$ and it is checked experimentally that between the $z$ axis and the XY plane the nonorthogonality is below $0.5^{\circ}$.

For monitoring magnetic field pulses a fluxgate magnetometer FG-500 is used (Table 4). 
Table 3. Channels involved in the study.

\begin{tabular}{lll}
\hline Sensor & Channel & Physical magnitude (units) \\
\hline Sourcing voltage $\left(V_{\mathrm{dd}}\right)$ & VREG & $\begin{array}{l}\text { Voltage sourcing the } \\
\text { magnetoresistive bridge }(\mathrm{V})\end{array}$ \\
Magnetic sensors axes & $\mathrm{X} 1, \mathrm{X} 2, \mathrm{Y} 1, \mathrm{Y} 2, \mathrm{Z1}, \mathrm{Z2}$ & Magnetic field $(\mathrm{nT})$ \\
Temperature sensors & $\mathrm{TMP} 1, \mathrm{TMP} 2$ & Temperature $\left({ }^{\circ} \mathrm{C}\right)$ \\
\hline
\end{tabular}

Table 4. Calibration of fluxgate magnetometers.

\begin{tabular}{lllllllll}
\hline Parameter & Specified & \multicolumn{3}{c}{ FG-100 } & & \multicolumn{3}{c}{ FG-500 } \\
\cline { 3 - 5 } \cline { 7 - 9 } & & $\mathrm{X}$ & $\mathrm{Y}$ & $\mathrm{Z}$ & & $\mathrm{X}$ & $\mathrm{Y}$ & $\mathrm{Z}$ \\
\hline Orthogonality error & $\left(^{\circ}\right) \pm 0.1^{\circ}$ & $<0.1^{\prime}$ & $<0.1^{\prime}$ & $<0.1^{\prime}$ & & $<0.1^{\prime}$ & $<0.1^{\prime}$ & $<0.1^{\prime}$ \\
Offset error in zero field & $(\mathrm{nT}) \mathrm{F} . \mathrm{S}$. & 0 & -1.5 & 1 & & 1.5 & -10 & -0.5 \\
Scaling error & $(\%) @ 35 \mathrm{~Hz}, \pm 0.5 \%$ & 0.08 & 0.03 & -0.08 & & 0.07 & 0.15 & 0.20 \\
Frequency response & $(\%) \pm 5 \%$ & -0.06 & 0.06 & 0.08 & & 1.00 & 1.17 & 1.05 \\
Noise & $\left(\mathrm{pT}_{\mathrm{RMS}} \sqrt{ } \mathrm{Hz}^{-1}\right) @ 1 \mathrm{~Hz}$ & 19.3 & 12.3 & 15.6 & & 8.9 & 8.5 & 9.7 \\
\hline
\end{tabular}

A thermal chamber (Binder MK53) is employed to set and control the temperature during the characterization tests. This chamber makes it possible to apply temperatures from -70 to $180^{\circ} \mathrm{C}$, and to circulate dry $\mathrm{N}_{2}$ gas inside the chamber in order to control the humidity of the atmosphere. The $\mathrm{N}_{2}$ flow is kept between 1 and $5 \mathrm{~L} \mathrm{~min}^{-1}$. The measurement of the atmospheric humidity inside the chamber is performed by a Vaisala HMI31 humidity and temperature indicator, and always kept under $18 \%$. This is done to prevent water condensation in the low temperature range. No influence of humidity on our sensors' performance is observed.

For the characterization tests, the temperature register is performed by the included thermal chamber temperature sensors, those included in MOURA and two additional temperature sensors. These additional temperature sensors are two PT-1000 resistances calibrated by means of a SIKA TP 38165E, and connected to a data acquisition system (Agilent 3497A Automatic DAS, computer commanded).

For the calibration of the inclinometer a sine bar and gauge blocks with five values between 1.5 and $141.0 \mathrm{~mm}$ are used to generate the desired tilt angles around $x$ and $y$ axes $(\alpha$ and $\beta$ angles). The rotations are obtained with one of the cylindrical plugs leaning on the gauge blocks and the other on the surface plate. The accuracy of the method is better than $10^{\prime}$.

The next section describes the step-by-step calibration. Section 3.1 deals with the calibration at a reference temperature. Section 3.2 deals with the characterization with temperature of the magnetic parameters. Figure 3 shows the details of the main setups for these measurements.

\section{Methods and results}

This section describes the procedure followed for MOURA calibration.

The results shown here correspond to the measurements taken with the flipping operation. Therefore, the response of the $i$ axis (of the six measuring axes of the magnetometer) $B_{\text {MOURA, } i \text { corresponds to }}$

$\frac{\left(\mathrm{SET}_{i}-\mathrm{RESET}_{i}\right)}{2 \cdot \mathrm{VREG}}=\cos \theta_{i} \cdot B_{\mathrm{REAL}} \cdot \mathrm{GAIN}_{i}-\mathrm{OFFSET}_{i}$,

where $i=\mathrm{X} 1, \mathrm{X} 2, \mathrm{Y} 1, \mathrm{Y} 2, \mathrm{Z} 1, \mathrm{Z} 2$, with $\mathrm{SET}_{i}$ and $\mathrm{RESET}_{i}$ the registered magnetic signals from a given axis " $i$ " after the application of a SET and RESET pulse, respectively. VREG is the registered voltage sourcing the magnetoresistive bridge. $\theta_{i}$ is the angle between the direction of the field and the measurement direction of " $i$ " sensor. $B_{\text {REAL }}$ is the external magnetic field modulus. GAIN $i$ is the effective gain of the " $i$ " sensor. OFFSET $i$ is the offset of the " $i$ " sensor.

The sensor always acquires both Set and Reset data and thus it is always possible to use the same calibration data for the data without flipping.

MOURA temperature sensors had been previously calibrated by means of a $38165 \mathrm{E}$ system by SIKA TP giving rise to a polynomial fit. However, this calibration is not used in the present work, but the calibration is performed with the direct readings of the temperature sensors no matter what the real temperature is.

To avoid influence of the voltage source fluctuations, the output values are always normalized with the bridge voltage, which is monitored (Eq. 1).

The parameters affected by temperature are:

1. gain;

2. offset. 


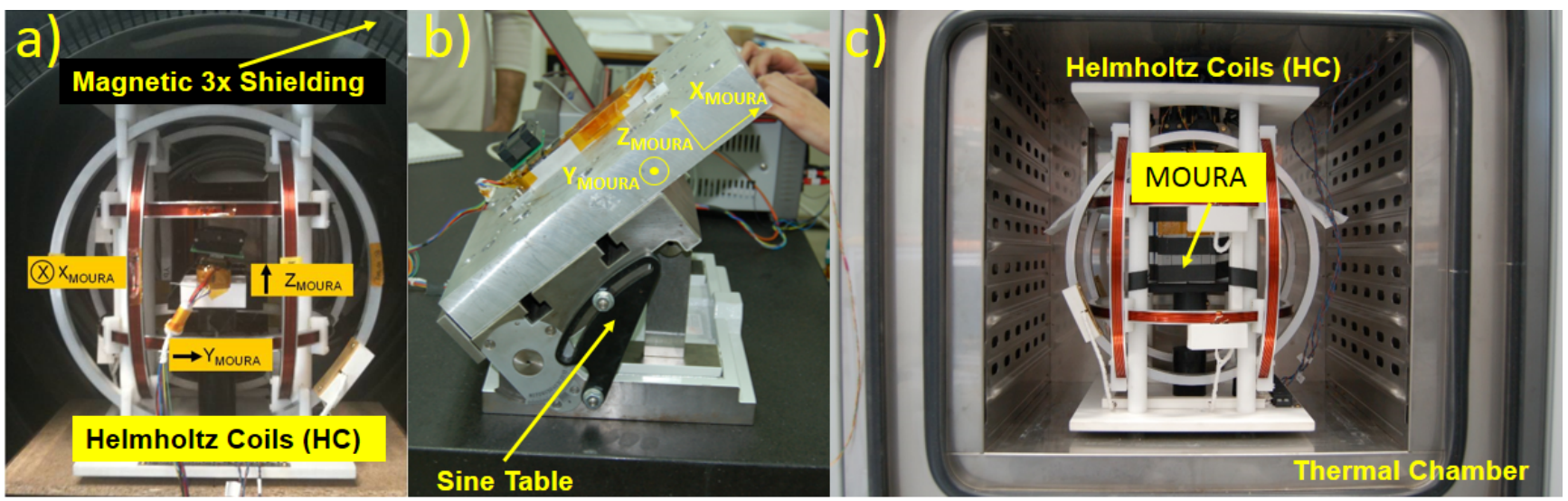

Figure 3. Different setups: (a) offset, gain and Euler angles characterization setup, (b) inclinometer characterization setup, (c) setup for gain characterization with temperature.

Therefore, MOURA response (for one of its axis) to a real magnetic field can be expressed as

$B_{\text {MOURA }}(T)_{i}=\cos \theta_{i} \cdot B_{\mathrm{REAL}} \cdot \mathrm{GAIN}_{i} \cdot\left(1-\Delta \mathrm{GAIN}_{i} \cdot\left(T-T_{\mathrm{G}}\right)\right)$

- OFFSET $_{i} \cdot\left(1-\Delta\right.$ OFFSET $\left._{i}\right) \cdot\left(T-T_{\text {OFFSET }}\right)$,

where $\triangle$ GAIN $_{i}$ is the normalized GAIN temperature variation rate, $\triangle$ OFFSET $_{i}$ is the normalized OFFSET temperature variation rate, $T_{\mathrm{G}}$ is the reference temperature for the gain, i.e. normalization temperature for $\mathrm{GAIN}_{i}$, and $T_{\text {OFFSET }}$ is the reference temperature for the offset, i.e. normalization temperature for $\mathrm{OFFSET}_{i}$. Note that these temperatures do not need to be the same but they are subject to room temperature variations (seasonal).

From now on we will use $M_{i}$ to refer to the " $i$ " sensor measurement and leave $\boldsymbol{B}_{\text {MOURA }}$ for the total magnetic vector.

\subsection{Room temperature characterization}

This section describes the room temperature characterization of the offsets, gains and output field generated by the offset coils.

\subsubsection{Characterization of MOURA magnetic offsets at room temperature}

The offset characterization of the two magnetic sensors components was performed inside a three-layer magnetic shielded chamber of $2.5 \mathrm{~m}^{3}$, previously characterized (at different points) by means of a three-axis fluxgate with minimum detectable fields of the order of $10 \mathrm{pT}$ (Fig. 3a).

Because the magnetic field inside the chamber $(\sim 0.1 \mathrm{nT})$ is lower than the minimum detectable field of the sensor ( $\sim 1 \mathrm{nT})$, passive compensation of the Earth's magnetic field was considered to be sufficient.

After warming up and thermal stabilization at room temperature $\left(\mathrm{TMP} 1=18.13 \pm 0.03^{\circ} \mathrm{C}\right.$ and $\mathrm{TMP} 2=19.21$ $\pm 0.03{ }^{\circ} \mathrm{C}$, with variations $\left.<0.1^{\circ} \mathrm{C} \mathrm{min}-1\right)$, MOURA data were acquired constantly during the whole process.

Magnetic sensors outputs were analysed. Mean values and standard deviations are shown in Table 5.

\subsubsection{Non-orthogonalities and Euler angle determination - gain characterization}

In this section we describe the procedure and results for the determination of the geometrical directions of MOURA sensor axes.

The registered signal of MOURA " $i$ " sensor, $M_{i}$, at room temperature can be written in vector expression as

$$
\begin{aligned}
& M_{i}=\left(\boldsymbol{B}_{\mathrm{REAL}} \cdot \boldsymbol{u}_{i}\right) \cdot \mathrm{GAIN}_{i}-\mathrm{OFFSET}_{i}, \\
& \boldsymbol{B}_{\mathrm{real}} \cdot \boldsymbol{u}_{i}=|\boldsymbol{B}| \cdot\left|\boldsymbol{u}_{i}\right| \cdot \cos \theta_{i}, \\
& M_{i}=|\boldsymbol{B}| \cdot \cos \theta_{i} \cdot \mathrm{GAIN}_{i}-\mathrm{OFFSET}_{i},
\end{aligned}
$$

with $\boldsymbol{u}_{i}$ being a unit vector in the measuring direction of " $i$ " sensor.

The external field, $\boldsymbol{B}_{\text {REAL }}$, is generated in the zero field chamber by the previously described set of HC. The sensor box is aligned with the axes of the HC. Hereinafter, MOURA basis will refer to the measuring directions of each three-axis sensor, and not to the box. Notice that the magnetic field generated by the $\mathrm{HC}$ in the $\mathrm{HC}$ basis will be denoted by $\boldsymbol{B}$ and the measurements of MOURA in MOURA basis will be denoted by $\boldsymbol{M}$ (Fig. 4).

If $\theta_{i}$ and GAIN $_{i}$ are unknown it is not possible to distinguish between a misalignment and a scale factor.

To simplify the problem and to calculate the most accurate values of the GAIN and misalignment of sensors with the external system of reference (HC) some approximations can be applied:

1. The three axes of the magnetometers and the $\mathrm{HC}$ are taken as orthogonal due to the construction properties, described in Sect. 2.2. 
Table 5. Gains and offset values as well as their temperature drifts.

\begin{tabular}{|c|c|c|c|c|}
\hline $\begin{array}{l}\text { SENSOR } 1 \\
\text { axis }\end{array}$ & $\begin{array}{c}\text { GAIN @ } \\
T_{\mathrm{G}}=\mathrm{TMP} 1= \\
25.9 \pm 0.2^{\circ} \mathrm{C}\end{array}$ & $\begin{array}{l}\Delta \text { GAIN }\left({ }^{\circ} \mathrm{C}^{-1}\right) \\
\text { (referred to } T_{\mathrm{G}} \text { ) }\end{array}$ & $\begin{array}{l}\text { OFFSET (nT) @ } \\
\mathrm{TMP} 1=18.13 \pm 0.03{ }^{\circ} \mathrm{C}\end{array}$ & $\begin{array}{l}\triangle \text { OFFSET }\left({ }^{\circ} \mathrm{C}^{-1}\right) \\
(\text { referred to TMP1) }\end{array}$ \\
\hline $\mathrm{X} 1$ & $0.910 \pm 0.003$ & $\left(-0.00370 \pm 5 \times 10^{-5}\right)$ & $764 \pm 5$ & $\left(-0.0037 \pm 5 \times 10^{-5}\right)$ \\
\hline Y1 & $0.902 \pm 0.002$ & $\left(-0.00382 \pm 7 \times 10^{-5}\right)$ & $-1130 \pm 16$ & $\left(-0.00450 \pm 7 \times 10^{-5}\right)$ \\
\hline $\mathrm{Z} 1$ & $0.832 \pm 0.003$ & $\left(-0.00384 \pm 4 \times 10^{-5}\right)$ & $1582 \pm 8$ & $\left(-0.00352 \pm 4 \times 10^{-5}\right)$ \\
\hline $\begin{array}{l}\text { SENSOR } 2 \\
\text { axis }\end{array}$ & $\begin{array}{c}\text { GAIN @ } \\
T_{\mathrm{G}}=\mathrm{TMP} 2= \\
25.6 \pm 0.2^{\circ} \mathrm{C}\end{array}$ & $\begin{array}{l}\Delta \mathrm{GAIN}\left({ }^{\circ} \mathrm{C}^{-1}\right) \\
\text { (referred to } T_{\mathrm{G}} \text { ) }\end{array}$ & $\begin{array}{l}\text { OFFSET (nT) @ } \\
\mathrm{TMP} 2=19.21 \pm 0.03{ }^{\circ} \mathrm{C}\end{array}$ & $\begin{array}{l}\triangle \text { OFFSET }\left({ }^{\circ} \mathrm{C}^{-1}\right) \\
(\text { referred to TMP2) }\end{array}$ \\
\hline $\mathrm{X} 2$ & $0.815 \pm 0.003$ & $\left(-0.00591 \pm 5 \times 10^{-5}\right)$ & $1107 \pm 3$ & $\left(-0.00200 \pm 5 \times 10^{-5}\right)$ \\
\hline $\mathrm{Y} 2$ & $0.807 \pm 0.001$ & $\left(-0.00621 \pm 9 \times 10^{-5}\right)$ & $-538 \pm 5$ & $\left(-0.00794 \pm 9 \times 10^{-5}\right)$ \\
\hline $\mathrm{Z} 2$ & $0.783 \pm 0.002$ & $\left(-0.00616 \pm 6 \times 10^{-5}\right)$ & $1427 \pm 17$ & $\left(-0.0379 \pm 4 \times 10^{-4}\right)$ \\
\hline
\end{tabular}

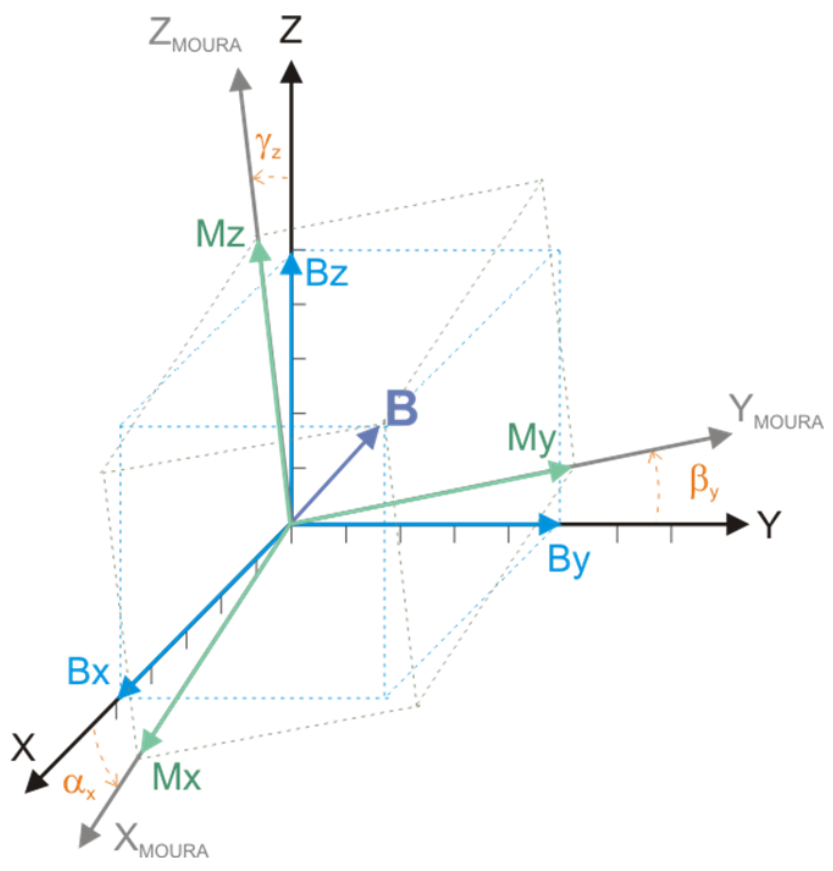

Figure 4. Approximation of system of reference of MOURA vs. external system of reference with the approximations taken into account.

2. The change of basis between HC and MOURA reference systems can be taken as a composition of small rotations around axes of the external reference system. Under this approximation it is not required the use of an unknown rotation matrix.

3. Gains of the different axes of the same sensor have similar values.

For each three-axis magnetometer (1 and 2), the angle between $\boldsymbol{B}_{X}$ and $\boldsymbol{M}_{X}$ is denoted as $\alpha_{x}$, between $\boldsymbol{B}_{Y}$ and $\boldsymbol{M}_{Y}$ as $\beta_{y}$ and between $\boldsymbol{B}_{Z}$ and $\boldsymbol{M}_{Z}$ as $\gamma_{z}$ (Fig. 4). Notice that these angles have two contributions: the already known nonorthogonality of the coils and the Euler angles referred to the $\mathrm{HC}$ system. These angles are to be determined for the two magnetometers composing the gradiometer.

In contrast with other highly precise calibration methods (Renaudin et al., 2010; Petrucha and Kaspar, 2009; Petrucha et al., 2009; Cai et al., 2010), in which a well calibrated and aligned three-axis goniometric platform is used, in the present case we have employed a method based on the calibration by means of the application of time varying circular magnetic fields (harmonic with a $\pi / 2$ phase shift between components) around MOURA, in the planes of the HC system. As a result of these sine-cosine circular fields, an elliptical response, due to the expected misalignment and different gain of each sensor axis, will be detected by MOURA sensors.

MOURA was fixed in the centre and aligned with the set of HC (Fig. 3a), taking as a reference the geometrical shape of its box: for this measurement, a high-precision container was made ad hoc in order to fit rigidly the magnetometer, and a set of laser theodolites was used to align $\mathrm{HC}$ and the sides of the container. Doing so, we could set MOURA and the set of $\mathrm{HC}$ in co-axial position, with a calculated misalignment below $0.1^{\prime}$.

The whole set was placed into the magnetic shielded chamber.

The calibration tests are performed in thermal equilibrium (thermal variations $<0.2{ }^{\circ} \mathrm{C} \mathrm{min}^{-1}$ ). MOURA nonorthogonalities between $i^{\prime}$ and $j^{\prime}$ axes (MOURA reference system) are determined by comparison of orthogonalities between MOURA and HC system ( $i$ and $j$ axes in HC reference system): $\Omega$ MOURAi $j^{\prime}$, and $\Omega \mathrm{HC} i j$. The comparison is performed by successive application of rotating magnetic fields in the different planes of the $\mathrm{HC}$ reference system (XY, ZX, YZ - Table 6) and the corresponding linear fit with MOURA synchronized readings (Fig. 5): 


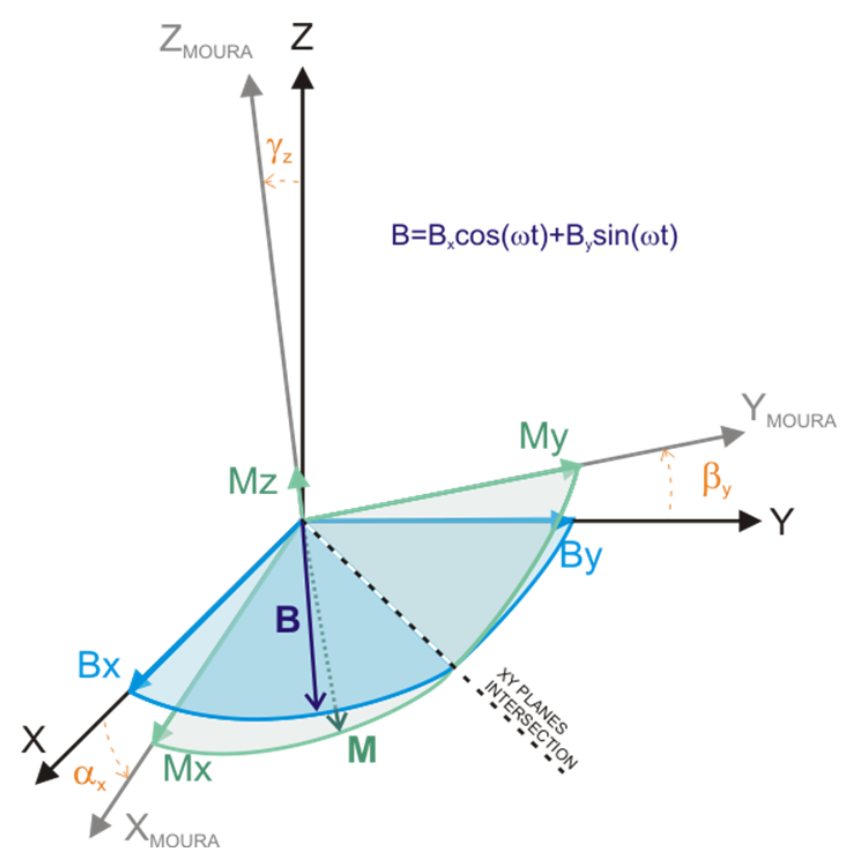

Figure 5. Sketch of the different shapes of magnetic field measured in external and MOURA reference systems.

$\Omega_{\mathrm{HC} i j}($ step $)=\arctan \left(\frac{B_{i}}{B_{j}}\right)$

$\Omega_{\text {MOURAi }^{\prime} j^{\prime}}($ step $)=\arctan \left(\frac{B_{i^{\prime}}}{B_{j^{\prime}}}\right)$;

$\Omega_{\mathrm{HC} i j}=\delta+P \cdot \Omega_{\mathrm{MOURAi}^{\prime} j^{\prime}}$.

$\delta$ is the misalignment between $i j$ and $i^{\prime} j^{\prime}$ HC and MOURA axes respectively. $P$ is the slope of the linear fitting between $\Omega_{\mathrm{HC} i j}$ and $\Omega_{\mathrm{MOURA} i^{\prime} j^{\prime}}$.

Room temperature $\operatorname{GAIN}_{x}, \operatorname{GAIN}_{y}, \operatorname{GAIN}_{z}$ calculation is performed by comparison of the MOURA registered magnetic signals and successive reference positive and negative signals of intensity $\left(P_{\mathrm{i}}^{+}\right.$and $\left.P_{\mathrm{i}}^{-}\right)$of 1 min duration applied in the different axes, using

$$
\begin{aligned}
& B_{\text {MOURA }}(T)_{\mathrm{i}}^{+}-B_{\text {MOURA }}(T)_{\mathrm{i}}^{-} \\
& =\cos \theta_{i} \cdot\left(P_{\mathrm{i}}^{+}-P_{\mathrm{i}}^{-}\right) \cdot \operatorname{GAIN}_{\mathrm{i}} \cdot\left(T_{\mathrm{G}}\right) .
\end{aligned}
$$

Note that $\mathrm{X} 1$ and $\mathrm{Y} 1$ have opposite sense directions to $\mathrm{X} 2$ and $\mathrm{Y} 2$, respectively, for engineering purposes. This methodology is valid because it has been previously checked that the response of the sensor is linear with the magnetic field being the correlation coefficient between MOURA output and applied field higher than 0.9998 in all axes.

The results from the fittings are presented in Table 5.

Once the linear fitting and then the misalignment angles between planes were obtained, it was possible to approximate the misalignment of each axis by direct composition. Under this approximation the gains for each axis were obtained by direct calculus employing Eq. (5) and statistical
Table 6. Applied electrical currents in the different planes.

\begin{tabular}{lll}
\hline Plane & $\begin{array}{l}\text { Electrical current } \\
\left(\omega=1^{\circ} \text { step }^{-1}\right)\end{array}$ & Sequence of steps \\
\hline $\mathrm{XY}$ & $I_{x}(t)=60 \mathrm{~mA} \times \cos (\omega \times$ step $)$ & From 1 to 360 \\
& $I_{y}(t)=60 \mathrm{~mA} \times \sin (\omega \times$ step $)$ & \\
\hline $\mathrm{ZX}$ & $I_{z}(t)=60 \mathrm{~mA} \times \cos (\omega \times$ step $)$ & From 361 to 721 \\
& $I_{x}(t)=60 \mathrm{~mA} \times \sin (\omega \times$ step $)$ & \\
\hline $\mathrm{YZ}$ & $I_{y}(t)=60 \mathrm{~mA} \times \cos (\omega \times \operatorname{step})$ & From 722 to 1082 \\
& $I_{z}(t)=60 \mathrm{~mA} \times \sin (\omega \times$ step $)$ & \\
\hline
\end{tabular}

Table 7. Parameters $\delta$ and $P$ of Eq. (4).

\begin{tabular}{lll}
\hline $\begin{array}{l}\text { MOURA/HC } \\
\text { planes }\end{array}$ & $\delta\left(^{\circ}\right)$ & $P$ \\
\hline $\mathrm{X} 1 \mathrm{Y} 1 / \mathrm{XY}$ & $0.64 \pm 0.05$ & $-0.997 \pm 0.001$ \\
$\mathrm{X} 1 \mathrm{X} 1 / \mathrm{XZ}$ & $7.3 \pm 0.2$ & $-0.986 \pm 0.004$ \\
$\mathrm{Y} 1 \mathrm{Z} 1 / \mathrm{YZ}$ & $-0.42 \pm 0.2$ & $1.005 \pm 0.004$ \\
\hline $\mathrm{X} 2 \mathrm{Y} 2 / \mathrm{XY}$ & $1.76 \pm 0.05$ & $-0.997 \pm 0.001$ \\
$\mathrm{X} 2 \mathrm{Z} 2 / \mathrm{XZ}$ & $-5.3 \pm 0.1$ & $0.973 \pm 0.002$ \\
$\mathrm{Y} 2 \mathrm{Z} 2 / \mathrm{YZ}$ & $1.12 \pm 0.1$ & $-1.006 \pm 0.003$ \\
\hline
\end{tabular}

corrections of the measured magnetic moduli. The results are shown in Table 7.

With this correction, relative errors in the measurement of the field with the different axes are below $0.3 \%$ except for the case of the $\mathrm{Y} 1$ sensor, which has an error of up to $0.9 \%$.

\subsubsection{Characterization of output fields of the offset coils}

The characterization of the offset coils constant (field vs. current) needs to be performed since the field vs. current provided by the manufacturer is subject to an error and these coils are used for the calibration of the sensors prior to use. Also these coils are used to extend the dynamic range of the magnetometer when it is saturated in the automated mode.

This characterization is performed in the same conditions as the gain characterization (using the same $\mathrm{HC}$ system in the zero-field chamber).

Decreasing and increasing field ramps are applied in 126 steps (between -45655 and $45665 \mathrm{nT}$ ). At room temperature, the field generated by the different offset coils is between 0.8617 and $0.9116 \pm 0.0003$ times that generated by the external field (Table 11). More details are given in Sect. 3.2.3, where the temperature calibration data are shown.

\subsubsection{Inclinometer and gravimeter characterization}

In order to be able to derive the horizontal and vertical components of the field and thus its orientation, it was required to characterize the response of the tilt angle detector, a threeaxis accelerometer. This calibration is not direct since the ac- 
Table 8. Tilt angles around $+X$ ( $\alpha$ tilt angle) and experimental values (converted into $g$ ) for the first five steps.

\begin{tabular}{lccccl}
\hline$\alpha\left({ }^{\circ}\right)$ & $\Delta \alpha\left(^{\circ}\right)$ & ACC_X $(\mathrm{g})$ & ACC_Y $(\mathrm{g})$ & ACC_Z $(\mathrm{g})$ & ACC $(\mathrm{g})$ \\
\hline 4.9719 & $< \pm 0.16$ & 0.2299 & 0.7839 & -0.4297 & 0.92302 \\
11.5369 & $< \pm 0.16$ & 0.3043 & 0.7182 & -0.4747 & 0.9131 \\
19.4711 & $< \pm 0.16$ & 0.3953 & 0.6261 & -0.5170 & 0.9031 \\
30.0000 & $< \pm 0.16$ & 0.5080 & 0.4920 & -0.5483 & 0.8948 \\
41.8103 & $< \pm 0.16$ & 0.6411 & 0.3583 & -0.6114 & 0.9556 \\
\hline
\end{tabular}

celerometer is placed on a PCB tilted $45^{\circ}$ over the horizontal and rotated by an angle of $-90^{\circ}$ with respect to the MOURA box $z$ axis, and by $45^{\circ}$ with respect to the MOURA $y$ axis. This rotation aims to linearize the accelerometer components response at zero tilt.

Also for field work it is interesting to characterize the gravity measurements in order to complement the magnetic measurements with gravity (low resolution) ones.

The following procedure designed by INTA and named "Procedure of Measurement Levels Calibration" consisted in the comparison between the real inclinations of the sine bar around $x$ and $y$ axes ( $\alpha$ and $\beta$ angles) with the measurements provided by the accelerometer axis (Table 8 ). The sequence of tilt is: zero tilt - maximum tilt - minimum tilt (negative) - zero tilt with five different values of tilt in absolute value (Fig. 3b).

The accelerometer and MOURA box system systems of reference are designed by $\{\mathrm{ACC}\}$ and $\{\mathrm{MOU}\}$, respectively.

The theoretical change of basis matrix, $\mathbf{B}$, between $\{\mathrm{ACC}\}$ and $\{\mathrm{MOU}\}$ and the inverse, $\mathbf{B}^{-1}$, with their respective errors, are

$$
\begin{aligned}
& \mathbf{B}=\frac{1}{2}\left[\begin{array}{lll}
\sqrt{2} & 1 & 1 \\
-\sqrt{2} & 1 & 1 \\
0 & -\sqrt{2} & \sqrt{2}
\end{array}\right] ; \\
& \Delta \mathbf{B}=\left[\begin{array}{lll}
0.0371 & 0.0524 & 0.0524 \\
0.0371 & 0.0524 & 0.0524 \\
0 & 0.0371 & 0.0371
\end{array}\right] \\
& \mathbf{B}^{-1}=\frac{1}{2}\left[\begin{array}{lll}
\sqrt{2} & -\sqrt{2} & 0 \\
1 & 1 & -\sqrt{2} \\
1 & 1 & \sqrt{2}
\end{array}\right] ; \\
& \Delta \mathbf{B}^{-1}=\left[\begin{array}{lll}
0.0371 & 0.0371 & 0 \\
0.0524 & 0.0524 & 0.0371 \\
0.0524 & 0.0524 & 0.0371
\end{array}\right] .
\end{aligned}
$$

Table 9 displays the relative errors between the measured and theoretical values of $\alpha$. The measured error allows us to calculate a slight extra rotation around the $z$ axis (an angle of $-1.7686^{\circ}$ ) due to the experimental positioning of the accelerometer PCB.

The new change of basis matrix corresponds to

$$
\mathbf{B}_{\exp }=\mathbf{B R}_{\varepsilon}=\frac{1}{2}\left[\begin{array}{lll}
\sqrt{2} & 1 & 1 \\
-\sqrt{2} & 1 & 1 \\
0 & -\sqrt{2} & \sqrt{2}
\end{array}\right]\left[\begin{array}{lll}
0.9995 & -0.0309 & 0 \\
0.0309 & 0.9995 & 0 \\
0 & 0 & 1
\end{array}\right] .
$$

Table 9. Relative error between experimental 1 and theoretical values of $\alpha$ for different $\alpha$.

\begin{tabular}{lcrrr}
\hline$\alpha\left(^{\circ}\right)$ & ACC_X $(\mathrm{g})$ & ACC_Y $(\mathrm{g})$ & ACC_Z $(\mathrm{g})$ & ACC $(\mathrm{g})$ \\
\hline 5 & $2.7 \%$ & $-1.5 \%$ & $0.0 \%$ & $-0.9 \%$ \\
12 & $3.5 \%$ & $-3.5 \%$ & $-0.5 \%$ & $-2.0 \%$ \\
19 & $4.6 \%$ & $-6.8 \%$ & $-1.2 \%$ & $-3.1 \%$ \\
30 & $4.8 \%$ & $-12.3 \%$ & $-2.8 \%$ & $-3.9 \%$ \\
42 & $7.8 \%$ & $-15.0 \%$ & $5.4 \%$ & $2.6 \%$ \\
\hline
\end{tabular}

Notice that this matrix will have to be characterized for each experimental setup, i.e. each model will have its own change of basis matrix.

Experimental values of $\alpha$ and $\beta$ obtained subtracting the zero tilt measurement from those corresponding to the different inclinations can be adjusted easily to the real tilt values giving

$\alpha_{\mathrm{EXP}}\left({ }^{\circ}\right)=1.0894 \cdot \alpha_{\mathrm{ref}}\left({ }^{\circ}\right)+0.7268^{\circ}$

$\beta_{\mathrm{EXP}}\left({ }^{\circ}\right)=0.9779 \cdot \beta_{\text {ref }}\left({ }^{\circ}\right)-1.7475^{\circ}$.

But these values have a slight difference from those derived from the accelerometer measurements in the MOURA box reference system:

$\alpha_{\mathrm{EXP}}^{\prime}\left({ }^{\circ}\right)=\arctan \left(\frac{\mathrm{MOU} \_\mathrm{Y}}{\mathrm{MOU} Z \mathrm{Z}}\right)=\alpha_{\mathrm{EXP}}\left({ }^{\circ}\right)-7.2890^{\circ}$
$\beta_{\mathrm{EXP}}^{\prime}\left(^{\circ}\right)=-\arctan \left(\frac{\mathrm{MOU} \_\mathrm{X}}{\mathrm{MOU} Z \mathrm{Z}}\right)=\beta_{\mathrm{EXP}}\left(^{\circ}\right)+21.4369^{\circ}$.

Consequently, the equations for the real inclinations around $x$ and $y$ axes from the accelerometer measurements in MOURA box reference system are

$\alpha\left(^{\circ}\right)=0.9179 \cdot \arctan \left(\frac{\text { MOU_Y }}{\text { MOU_Z }}\right)+6.0237^{\circ}$
$\beta\left(^{\circ}\right)=-1.0226 \cdot \arctan \left(\frac{\text { MOU_X }}{\text { MOU_Z }}\right)-20.1347^{\circ}$.

These data permit the determination of the inclination with errors up to $3 \%$ in $\alpha$ for $-30^{\circ}<\alpha<+30^{\circ}$, and of $6 \%$ in $-30^{\circ}<\beta<+30^{\circ}$. A better adjustment with errors up to $1 \%$ in $\alpha$ for $-40^{\circ}<\alpha<+40^{\circ}$, and of $3 \%$ in $-40^{\circ}<\beta<+40^{\circ}$, can be obtained with the following polynomial fit (Fig. 6):

$$
\begin{aligned}
\alpha\left(^{\circ}\right) & =-0.0012 \cdot \arctan 2\left(\frac{\text { MOU_Y }}{\text { MOU_Z }}\right) \\
& +0.8921 \cdot \arctan \left(\frac{\text { MOU_Y }}{\text { MOU_Z }}\right)+6.5543^{\circ}
\end{aligned}
$$



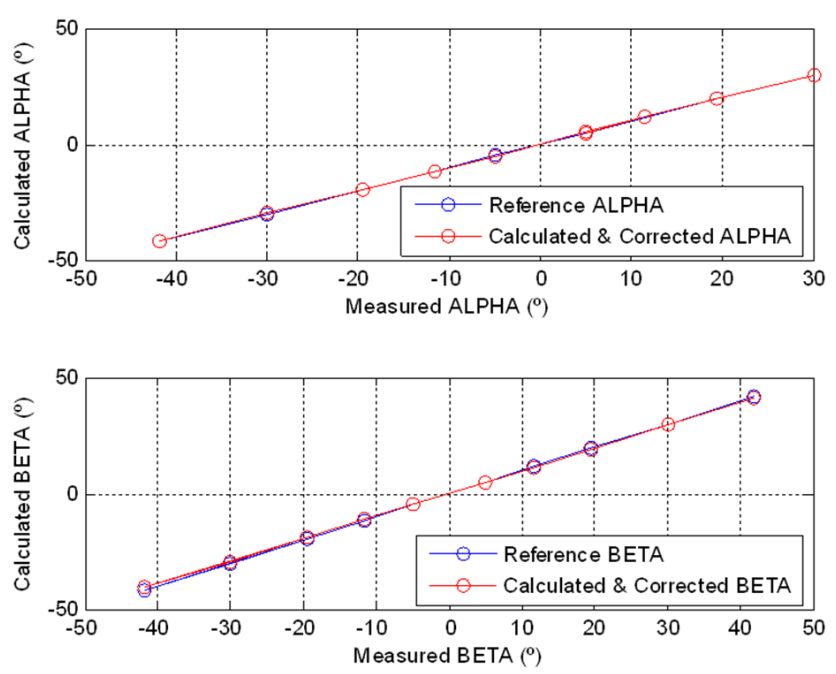

Figure 6. Corrected values of the tilt angles.

$$
\begin{aligned}
\beta\left({ }^{\circ}\right) & =0.0038 \cdot \arctan ^{2}\left(\frac{\text { MOU_X }}{\text { MOU_Z }}\right) \\
& -0.8656 \cdot \arctan \left(\frac{\text { MOU_X }}{\text { MOU_Z }}\right)-20.3296^{\circ} .
\end{aligned}
$$

Also the gravimeter readings need to be calibrated since they are very dependent on the tilt angle measurements.

Without correction the errors in the gravity modulus are of $1 \%$ for $\alpha= \pm 10^{\circ}$, but of the order of $5 \%$ in $\beta= \pm 10^{\circ}$. By means of a quadratic correction with the tilt angles and considering that $\alpha$ and $\beta$ are totally independent, the error is reduced to $\pm 0.0001 \mathrm{~g}(0.01 \%)$ for $\alpha= \pm 40^{\circ}$ and $\pm 0.004 \mathrm{~g}$ $(0.4 \%)$ for $\beta= \pm 40^{\circ}\left(g=9.8 \mathrm{~m} \mathrm{~s}^{-2}\right)$.

\subsection{Temperature-dependent characterization}

It is known that most of magnetic sensors have a temperaturedependent response, and therefore magnetic sensors need to undergo a temperature characterization when they are used in conditions of changing temperatures. Also the response of the conditioning electronics can change greatly when subject to huge temperature fluctuations.

The issue then is to determine the temperature of the device (core of the sensor, amplifier ... ) whose response varies with the temperature. This is a very complicated problem since normally the only accessible part of the device is the package. In the steady state (thermal dynamic equilibrium), the temperature of the package can be assumed as an indicator of the core temperature, though this can have a nonnegligible error when there are temperature gradients or/and fast temperature variations with time. Also the flipping of the AMR sensors implies temperature variations of the core. This situation makes it necessary to find an optimal working mode, which involves a trade-off between thermal changes, acquisition frequency and samples to average.
In this work we focus on a practical solution consisting in the characterization of the thermal behaviour in the steady state. Therefore, we focus on the two temperature channels, namely TMP1 and TMP2, corresponding to temperature sensors placed on top of the magnetic sensors. As has been introduced, these temperature sensors were not in close contact with the active sensing element of the magnetic sensors, i.e. magnetoresistive bridges, and therefore they are not expected to provide an accurate measurement of the magnetic sensors' instant temperatures. In addition, in this work it is considered that the orientation angles do not change by means of thermal expansion and contraction. This assumption responds to the fact that the calculated maximum angle deviation due to the worst case of an anisotropic thermal expansion is $0.015^{\circ}$ approximately, of the order of the resolution limit of the sensor.

\subsubsection{Offset characterization with temperature}

The variation of the offset with temperature was formerly estimated with the daily fluctuation of the temperature outside the building $\left(10-30^{\circ} \mathrm{C}\right)$. It was observed that the variation of the offset with temperature was very similar to that of the gain. This test was performed inside a shielding chamber with a field stability better than $1.5 \mathrm{nT}$. Therefore the offset observed is only attributed to the variations of temperature inside the chamber, which are registered and are in good correlation with the offset values monitored. Consequently, for the extended range of temperature, both variations with temperature will be considered equivalent, i.e. $\triangle \mathrm{OFFSET}=\triangle \mathrm{GAIN}$.

This assumption will be corrected with the long term records at San Pablo de los Montes Observatory with the local temperature data (Sect. 4).

\subsubsection{Gain characterization with temperature $-V_{\text {REG }}$ compensation}

The extended expression of Eq. (1), the expression of the measured fields in the different axes, as a function of temperature is

$$
\begin{aligned}
& M_{i}=\left(\boldsymbol{B}_{\mathrm{REAL}} \cdot \boldsymbol{u}_{i}\right) \cdot \operatorname{GAIN}_{i}\left(1-\Delta \operatorname{GAIN}\left(T-T_{\mathrm{G}}\right)\right) \\
& -\operatorname{OFFSET}_{i}\left(1-\triangle \operatorname{OFFSET}_{i}\left(T-T_{\text {OFFSET }}\right)\right) \text {; } \\
& \boldsymbol{B}_{\mathrm{REAL}} \cdot \boldsymbol{u}_{i}=|\boldsymbol{B}| \cdot\left|\boldsymbol{u}_{i}\right| \cdot \cos \theta_{B_{\mathrm{REAL}} M_{i}} ; \\
& M_{i}=|\boldsymbol{B}| \cdot \cos \theta_{B_{\mathrm{REAL}} M_{i}} \cdot \operatorname{GAIN}_{i}\left(1-\Delta \operatorname{GAIN}\left(T-T_{\mathrm{G}}\right)\right) \\
& -\operatorname{OFFSET}_{i}\left(1-\triangle \operatorname{OFFSET}_{i}\left(T-T_{\text {OFFSET }}\right)\right) \text {. }
\end{aligned}
$$

Since the magnetic noise in the thermal chamber is higher than the precision of MOURA, it is not possible to control or monitor the magnetic field with the required precision and to discern absolute variations in the offset (OFFSET) and gain (GAIN) of MOURA. However, due to the linearity of the output with the field, it is possible to calculate the variation of the relative gain $\left(\triangle \mathrm{GAIN}_{i}\right)$ by the measurement of the vari- 


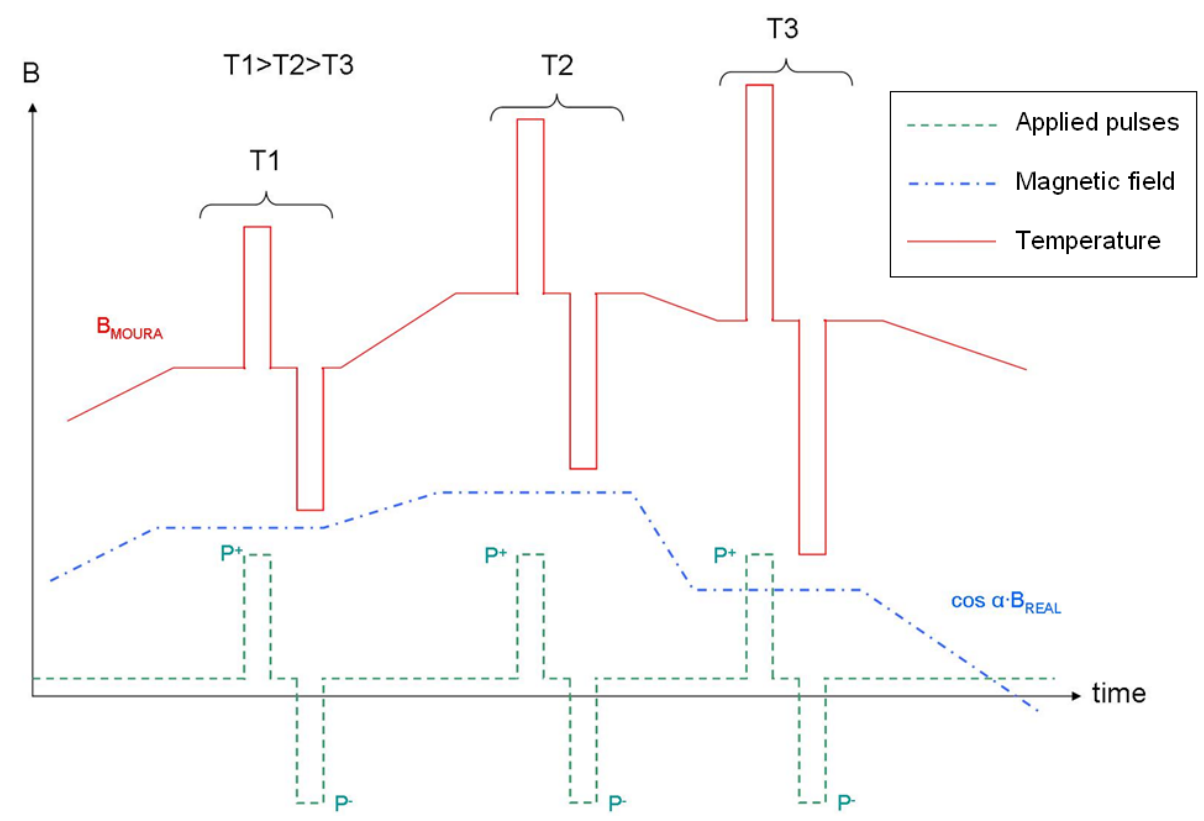

Figure 7. Sketch of applied pulses, real external magnetic field, registered signal by MOURA for different temperatures (T1, T2 and T3) as a function of time.

ation of the controlled amplitude between two applied magnetic pulses with the same modulus and direction but opposite polarization, assuming that the variation of the external magnetic field is much slower than the duration of the pulses (Fig. 3c). These pulses are denoted as $P^{+}$and $P^{-}$(Fig. 7).

MOURA sensors' response for $P^{+}$and $P^{-}$pulses will be denoted by $B_{\text {MOURA }}(T)_{i}^{+}$and $B_{\text {MOURA }}(T)_{i}^{-}$, respectively:

$$
\begin{aligned}
& B_{\text {MOURA }}(T)_{i}^{+} \\
& =\cos \theta_{i} \cdot P^{+} \cdot \operatorname{GAIN}_{i} \cdot\left(1-\Delta \operatorname{GAIN}_{i} \cdot\left(T-T_{\mathrm{G}}\right)\right) \\
& -\operatorname{OFFSET}_{i} \cdot\left(1-\Delta \mathrm{OFFSET}_{i}\right) \cdot\left(T-T_{\mathrm{OFFSET}}\right) B_{\mathrm{MOURA}}(T)_{i}^{-} \\
& =\cos \theta_{i} \cdot P^{-} \cdot \operatorname{GAIN}_{i} \cdot\left(1-\Delta \mathrm{GAIN}_{i} \cdot\left(T-T_{\mathrm{G}}\right)\right) \\
& -\operatorname{OFFSET}_{i} \cdot\left(1-\Delta \mathrm{OFFSET}_{i}\right) \cdot\left(T-T_{\mathrm{OFFSET}}\right)
\end{aligned}
$$

Subtracting the pulses,

$$
\begin{aligned}
& \frac{B_{\text {MOURA }}(T)_{i}^{+}-B_{\text {MOURA }}(T)_{i}^{-}}{2} \\
& =\cos \theta_{i} \cdot|2 P| \cdot \operatorname{GAIN}_{i} \cdot\left(1-\Delta \operatorname{GAIN}_{i} \cdot\left(T-T_{\mathrm{G}}\right)\right) \\
& =M_{i}^{\mathrm{A}}(T),
\end{aligned}
$$

where $M_{i}^{\mathrm{A}}$ is the averaged amplitude of the magnetic pulses measured by the $i$ axis of MOURA.

The magnetic field pulses are monitored by means of a three-axis fluxgate (FG-500). The accuracy of the magnetic field depends on the current in the circuit, which is controlled better than $1 \%$. Although it is not possible to determine analytically the absolute $\operatorname{GAIN}_{i}$ and $\theta_{i}$, i.e. the metrics and orthogonal projection from the $\mathrm{HC}$ system to reference system of MOURA, it is possible to normalize the obtained signals, using for the normalization the signal obtained at a reference temperature $\left(T_{\mathrm{G}}\right)$ :

$$
\begin{aligned}
& M_{i}^{\mathrm{A}}(T) / M_{i}^{\mathrm{A}}\left(T_{\mathrm{G}}\right)=\frac{\cos \theta_{i} \cdot|P| \cdot \operatorname{GAIN}_{i} \cdot\left(1-\Delta \operatorname{GAIN}_{i} \cdot\left(T-T_{\mathrm{G}}\right)\right)}{\cos \theta_{i} \cdot|P| \cdot \operatorname{GAIN}_{i} \cdot\left(1-\Delta \operatorname{GAIN}_{i} \cdot\left(T_{\mathrm{G}}-T_{\mathrm{G}}\right)\right)} \\
& M_{i}^{\mathrm{A}}(T) / M_{i}^{\mathrm{A}}\left(T_{\mathrm{G}}\right)=\left(1-\Delta \operatorname{GAIN}_{i} \cdot\left(T-T_{\mathrm{G}}\right)\right) .
\end{aligned}
$$

Applying a linear fitting of the normalized signals as a function of $T-T_{\mathrm{G}}$, it is possible to calculate $\Delta \mathrm{GAIN}_{i}$ as a function of temperature.

The test is carried out at six temperature values in the range of temperatures in which field measurements were performed, using as first reference the thermal chamber temperature controller: $-60,-30,0,15,45$, and $60{ }^{\circ} \mathrm{C}$. The registered humidity inside the chamber is $<18 \%$ for the test (as explained in Sect. 2.2). The square magnetic pulses along the six semi-axes were applied by means of a Keithley precision source $(10 \mathrm{~mA}$ current) supplied to the three pairs of $\mathrm{HC}$ simultaneously at thermal equilibrium $<0.1{ }^{\circ} \mathrm{C} \mathrm{min}{ }^{-1}$ (Table 9). The amplitude of each magnetic pulse was taken as the mean absolute value of each pulse applied along the same axis (positive and negative pulse). The registered magnetic field amplitudes were normalized to that obtained at room temperature: $\mathrm{TMP} 1=25.9 \pm 0.2{ }^{\circ} \mathrm{C}$ and $\mathrm{TMP} 2=25.6 \pm 0.2^{\circ} \mathrm{C}$. Two additional temperature sensors (calibrated PT-1000, denoted as TT and TL) were placed on the top (TT) and on a side (TL) of MOURA in order to guarantee thermal equilibrium. Since the level of magnetic noise generated by the hardware of the thermal chamber (mainly rotor and pumps) makes it impossible to obtain suitable accurate data, the thermal chamber was switched off when the pulses were applied (Fig. 8). 


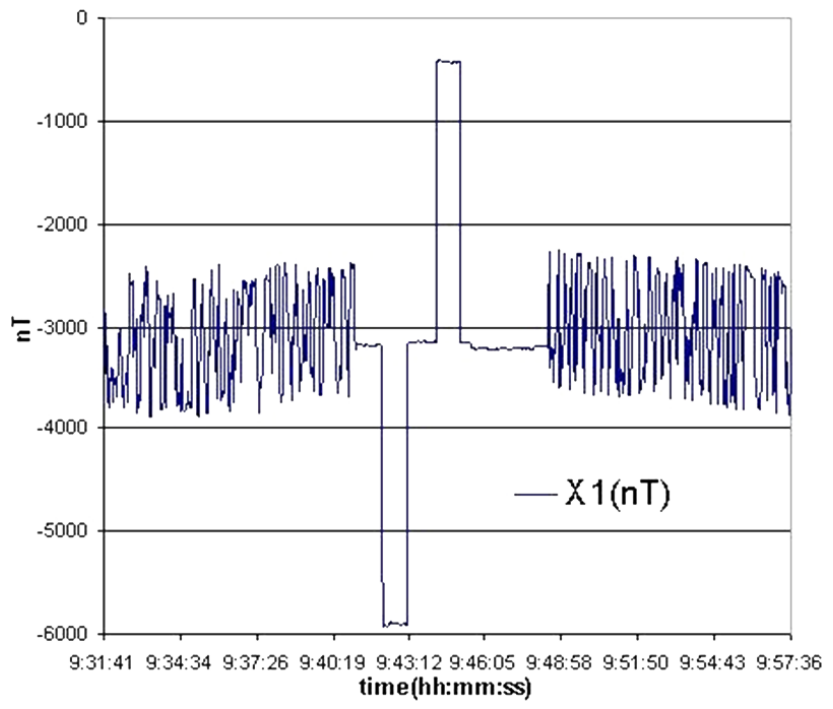

Figure 8. Detailed view of the register data by Sensor $1 x$ axis, minutes before and after the application of magnetic pulses (thermal chamber ON-OFF).

These variations of temperature affect the voltage sourcing of the magnetoresistive bridges. VREG has a variation with temperature of $0.1 \%$. The variation is recorded and will also be taken into account for the response correction.

The thermal chamber control is switched off for the measuring. The obtained values of amplitude for each axis were normalized by those obtained at $\mathrm{TMP} 1=25.9^{\circ} \mathrm{C}$ and $\mathrm{TMP} 2=25.6^{\circ} \mathrm{C}$. These normalized amplitudes were linearly fitted with the corresponding temperature $\left(T-25.9^{\circ} \mathrm{C}\right.$ for Sensor 1 data and $T-25.6^{\circ} \mathrm{C}$ for Sensor 2 data) (Fig. 9).

The coefficients for the thermal drift correction of the magnetic data $(\triangle$ GAIN) for each axis are presented in Table 5. For example, the gain compensation with temperature in Eq. (17) for the $x$ axis of Sensor 1 is

$$
\begin{aligned}
& \Delta \operatorname{GAIN}_{\mathrm{X} 1} \cdot(T-\mathrm{TG}) \\
& =\left(-0.00370 \pm 5 \times 10^{-5}\right)^{\circ} \mathrm{C}^{-1} \cdot\left[\operatorname{TMP} 1\left({ }^{\circ} \mathrm{C}\right)-25.9^{\circ} \mathrm{C}\right]
\end{aligned}
$$

\subsubsection{Offset coils characterization with temperature}

In this section the thermal variation of the offset coils constant (nT nT ${ }^{-1}$ or $\mathrm{nT} \mathrm{mA}^{-1}$ ) is calibrated. For simplicity only Sensor 1 parameters are displayed.

This characterization is performed by means of a relative measurement of the constant variation with temperature and then referred to the reference temperature in a similar way as the gain characterization with temperature.

In this case, two ramps (Ramp I: decreasing from 45665 to $-45665 \mathrm{nT}$, and Ramp II: increasing from -45665 to $45665 \mathrm{nT})$ of 126 steps $(4.56 \mathrm{~mA})$ have been applied with the offset coils.
Table 10. Temperature registers and their temporal variation.

\begin{tabular}{lrrrr}
\hline Measurement & $\mathrm{TT}\left({ }^{\circ} \mathrm{C}\right)$ & $\mathrm{TL}\left({ }^{\circ} \mathrm{C}\right)$ & $\mathrm{TMP} 1\left({ }^{\circ} \mathrm{C}\right)$ & $\mathrm{TMP} 2\left({ }^{\circ} \mathrm{C}\right)$ \\
\hline 1 & $59.4 \pm 0.1$ & $58.9 \pm 0.2$ & $50.4 \pm 0.1$ & $50.04 \pm 0.04$ \\
2 & $32.6 \pm 0.2$ & $32.2 \pm 0.1$ & $25.9 \pm 0.1$ & $25.6 \pm 0.1$ \\
3 & $5.4 \pm 0.2$ & $4.1 \pm 0.1$ & $-0.3 \pm 0.2$ & $-0.6 \pm 0.2$ \\
4 & $16.6 \pm 0.1$ & $17.3 \pm 0.1$ & $11.8 \pm 0.2$ & $11.55 \pm 0.2$ \\
5 & $44.8 \pm 0.1$ & $45.4 \pm 0.1$ & $38.4 \pm 0.1$ & $38.2 \pm 0.1$ \\
6 & $58.4 \pm 0.2$ & $58.8 \pm 0.2$ & $50.6 \pm 0.1$ & $50.51 \pm 0.01$ \\
\hline
\end{tabular}

Table 11. Offset coils constants at the different temperatures.

\begin{tabular}{lccc}
\hline \multirow{2}{*}{$\begin{array}{l}\text { TMP1 } \\
\left({ }^{\circ} \mathrm{C} \pm 0.05\right)\end{array}$} & \multicolumn{3}{c}{ Constant $\left(\mathrm{nTnT}^{-1}\right) \pm 0.0003$} \\
\cline { 2 - 4 } & & $\mathrm{Y} 1$ & $\mathrm{Z} 1$ \\
\hline 16.41 & 0.8879 & 0.9116 & 0.8617 \\
49.55 & 0.7743 & 0.8022 & 0.7644 \\
26.92 & 0.8518 & 0.8767 & 0.8293 \\
0.69 & 0.9406 & 0.9656 & 0.9086 \\
11.42 & 0.9045 & 0.9290 & 0.8760 \\
37.53 & 0.8160 & 0.8414 & 0.7961 \\
50.37 & 0.7722 & 0.7988 & 0.7564 \\
\hline
\end{tabular}

Previously it has been checked that the current passing through the offset coils does not increase the temperature of the magnetoresistors and thus does not change the response.

In order to obtain the values of the offset coil constant variation with temperature $\left(\mathrm{nT} \mathrm{nT}^{-1}{ }^{\circ} \mathrm{C}^{-1}\right)$, the abovementioned magnetic field ramps were applied at the five different temperatures in the same thermal chamber as the previous test.

In this case, MOURA temperature sensors were also employed to register the temperature variation during the test. The ramps were applied in thermal equilibrium $\left(<0.1^{\circ} \mathrm{C} \mathrm{min}^{-1}\right)$ with the control of the chamber switched off. Table 10 shows the temperature readings at thermal equilibrium at the testing temperatures obtained with the different temperature sensors. The control of the humidity $(<18 \%)$ was performed with $\mathrm{N}_{2}$.

An example of the obtained data is presented in Fig. 10. It can be seen that the offset value is higher than that obtained in the magnetic shielded chamber due to the lack of a magnetic clean environment.

The obtained coil constants for Sensor 1 from the linear fits for each ramp at different temperatures, and averaging data corresponding to Ramp I and Ramp II, are presented in Table 11 and shown in Fig. 11 as a function of TMP1 normalized to the reference temperature.

The obtained gains for each temperature were linearly fitted versus the registered temperature by the corresponding TMP sensor (Fig. 11). 
a)

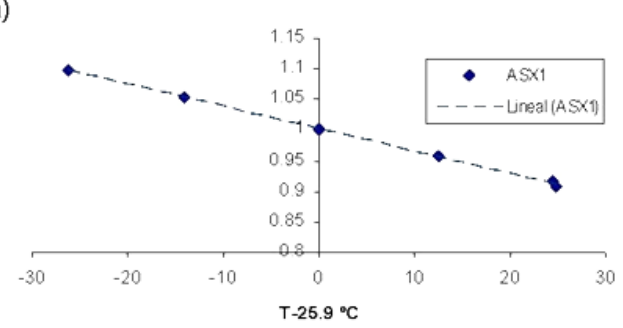

b)

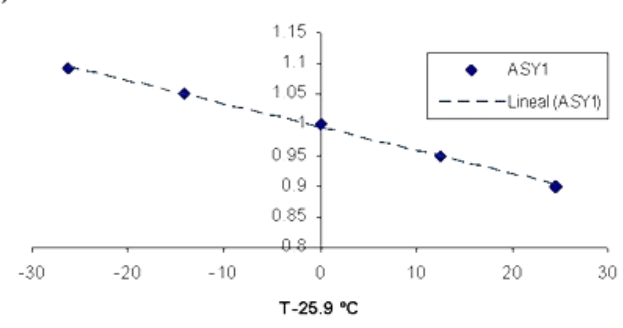

c)

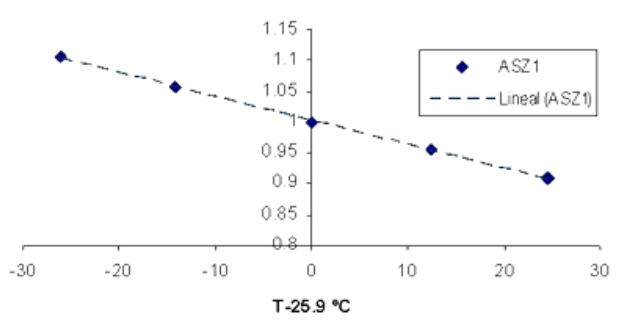

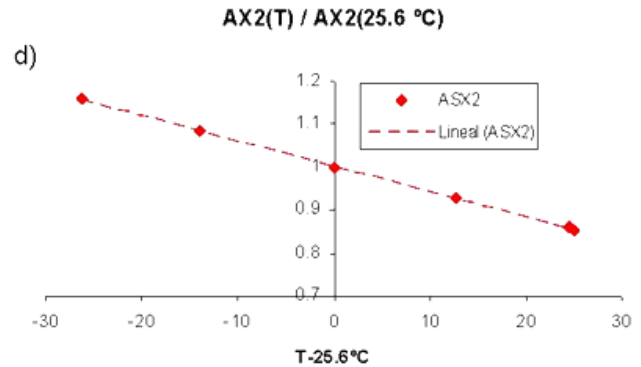

$\mathrm{AY} 2(\mathrm{~T}) / \mathrm{AY} 2\left(25.6^{\circ} \mathrm{C}\right)$

e)

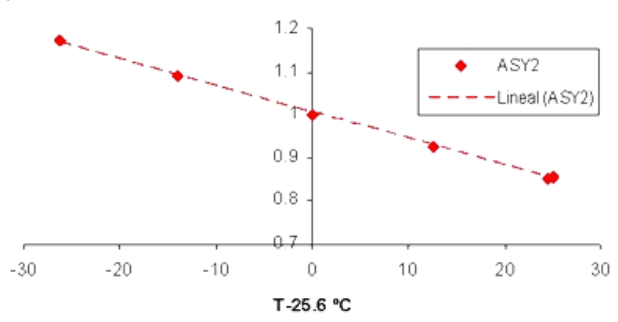

$\operatorname{AZ2}(\mathrm{T}) / \operatorname{AZ2}\left(25.6^{\circ} \mathrm{C}\right)$

f)

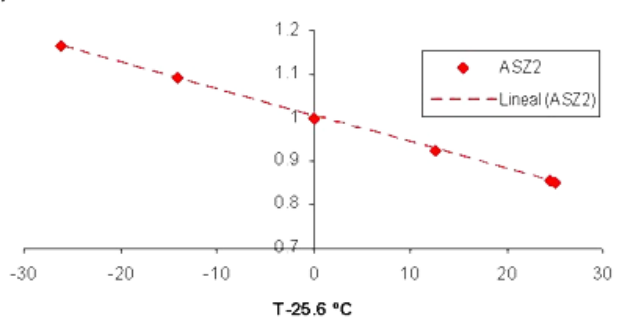

Figure 9. Normalized amplitude as a function of modified temperature for axis sensor (a) X1, (b) Y1, (c) Z1, (d) X2, (e) Y2, (f) Z2.

Table 12. Sensor 1 offset coils characterization with temperature.

\begin{tabular}{ll}
\hline$\Delta$ Constant axis & Value $\left(\left(\mathrm{nT} \mathrm{nT}^{-1}\right) \mathrm{C}^{-1}\right)$ \\
\hline$\Delta$ Constant $_{\mathrm{X} 1}$ & $-0.088034 \pm 7 \times 10^{-6}$ \\
$\Delta$ Constant $_{\mathrm{Y} 1}$ & $-0.086506 \pm 1 \times 10^{-5}$ \\
$\Delta$ Constant $_{\mathrm{Z} 1}$ & $-0.078218 \pm 4 \times 10^{-5}$
\end{tabular}

The thermal variations of the offset coils constants are presented in Table 12. For example, the compensation with temperature parameter of $\mathrm{X}$ coil of Sensor 1 is

$$
\begin{aligned}
& \Delta \text { Constant }_{\mathrm{X} 1}\left(\mathrm{nTnT}^{-1}\right) \cdot\left(\mathrm{TMP} 1-T_{\mathrm{ref}}\right)\left({ }^{\circ} \mathrm{C}\right) \\
& =\left(-0.088034 \pm 7 \times 10^{-6}\right)^{\circ} \mathrm{C}-1 \cdot(\mathrm{TMP} 1-25.9)\left({ }^{\circ} \mathrm{C}\right) .
\end{aligned}
$$

\section{Data comparison of MOURA and SPT reference magnetometers}

This section describes on the one hand the calibration of the offset with temperature by means of comparison with

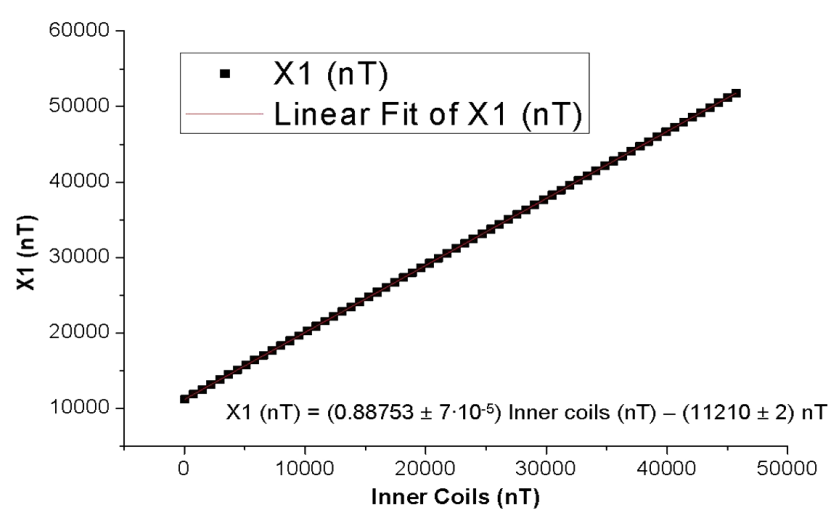

Figure 10. Data for Sensor $1 x$ axis "Ramp I" at $16.41^{\circ} \mathrm{C}(\mathrm{TMP} 1)$

another magnetometer (reference) at a temperature different from that of the laboratory, and on the other hand, a final measurement of a space weather event, as a demonstration of MOURA capabilities in terms of resolution. These measurements have been performed at the Geophysics Observatory of San Pablo-Toledo (SPT) $\left(39.547^{\circ} \mathrm{N}, 4.349^{\circ} \mathrm{W}\right)$ in Spain, during late January and February 2013 (offset drift with temperature) and during June, July and August 2013 


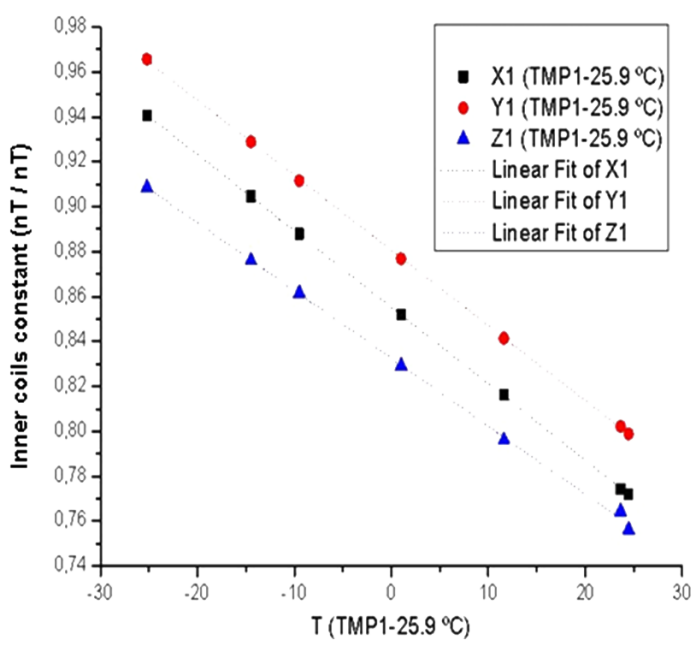

Figure 11. Linear fits of gain as a function of corrected temperature (TMP1-Tref).

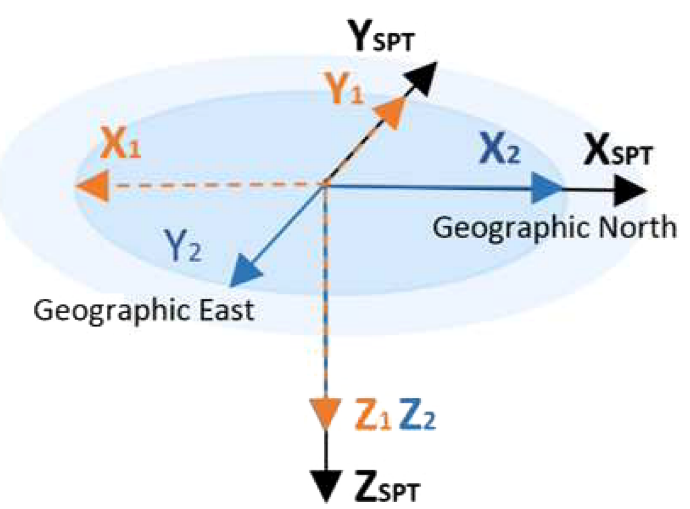

Figure 12. Relative axes of MOURA: X1, Y1, Z1 and X2, Y2, Z2 and SPT Observatory: XSPT, YSPT and ZSPT.

(geomagnetic storm). The comparison needs to be performed in situ for the large crustal magnetic anomalies variability in the peninsula and other factors like magnetic contamination (Martínez Catalán, 2012).

SPT belongs to INTERMAGNET (http://www. intermagnet.org), a global network of observatories (since 1997) and to the International Association of Geomagnetism and Aeronomy (IAGA) (available at http://www.iugg.org/IAGA). SPT has a fluxgate magnetometer FGE (Danish Meteorological Institute) and a fluxgate vector magnetometer Geomag M390. It is also equipped with Overhauser effect magnetometers GSM90 for calibration purposes. The instrumentation setup is completed by a dIdD Gemsystem equipment. Two declinometerinclinometers (Zeiss 010B) with a fluxgate Bartington probe are used for absolute weekly observations. This suite of magnetometers offers raw data, which are further corrected by the observatory (contamination removal: instrumentation faults or man-made interferences, and daily basis filtering).
Table 13. Percentage of transmission errors during five consecutive days (21-25 February 2013).

\begin{tabular}{lcc}
\hline & \multicolumn{2}{c}{ Errors percentage (\%) } \\
\cline { 2 - 3 } Axis & Sensor 1 & Sensor 2 \\
\hline $\mathrm{X}$ & 0.20 & 0.0 \\
$\mathrm{Y}$ & 0.00 & 4.2 \\
$\mathrm{Z}$ & 0.35 & 4.2 \\
\hline
\end{tabular}

In the present comparison partially treated and compensated available data will be used for the comparison. Final data are provided of the order of 1 year after the measurements.

For the test campaigns some auxiliary instrumentation was moved to SPT: MOURA instrument (with axes orientations as defined in Fig. 12), a voltage source with two output channels, a laptop, a 3G USB modem and a 82357B USB/GPIB interface (by Agilent Technologies).

Due to the distance between Toledo (test station) and Madrid (INTA headquarters), a 3G USB modem was used for remote control of the computer enabling all basic operations of MOURA. The complete setup with the elements described is shown in Fig. 13.

A first campaign between 21 and 25 February 2013 was used to refine the laboratory calibration.

During the acquisition, a percentage of erroneous data was detected (Table 13). This was attributed to transfer data errors during set and reset pulses or packing data errors. Retrieval software is able to detect and automatically suppress the errors.

The first campaign took place during quiet days. Figure 14 shows the variation of the different components of the magnetic field measured by MOURA sensors (Sensor 1 and Sensor 2) versus SPT for 21-24 February 2013. The typical terrestrial magnetic field daily variation can be seen, with a higher amplitude of the $\mathrm{X}$ component pointing to the north of the Earth during sunny hours, directly related with the exposure to the solar radiation during the day hours. MOURA data fit quite well with the reference data showing a daily variation of $\pm 35 \mathrm{nT}$ with highest values at around 12:00 to 14:00 UTC on the $X$ magnetic field component. A nonnegligible offset deviation of the MOURA data can be seen. This is related to the variation of the offset with the temperature. Note that offset calibration performed in the laboratory takes place at $18^{\circ} \mathrm{C}$ and the average temperature at SPT at the time of the campaign was $5^{\circ} \mathrm{C}$. This fact is used to correct the previous estimation performed in Sect. 3.2.1 according to the expression

$$
\frac{\Delta \text { Offset }}{\Delta T}\left(\mathrm{ppm}^{\circ} \mathrm{C}\right)=\frac{\frac{\text { Offset } \pm(\Delta \text { MOURA-SPT })-1}{\text { Offset }}}{T_{\text {Offset }}-T_{\text {SPT }}} \cdot 10^{6} .
$$

The resulting values are given in Table 5. As well as in the drift of gain with temperature, the dispersion of the offset drift with temperature is very wide, which makes it necessary 


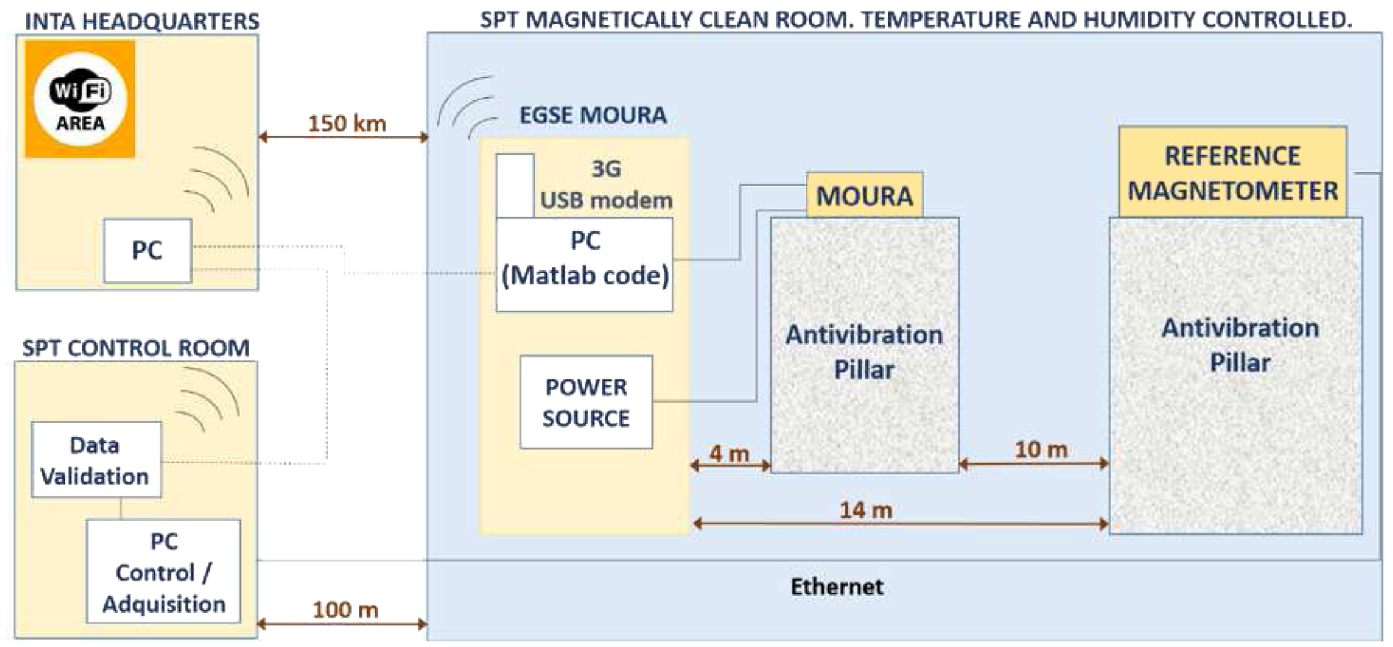

Figure 13. Setup of the measurements.

to screen the sensors to be used in the FM and filter the most suitable for the purpose.

After this last correction of the offset drift with temperature, and the corresponding modification of the retrieval software, a new campaign is performed with the double objective to validate the calibration and to demonstrate the suitability of the sensor to measure the space weather events. For this, the three months period from June to August 2013, with some solar activity, was selected. Figure 15 shows the data corresponding to the geomagnetic storm that occurred on 28 and 29 June: the horizontal component of MOURA sensors 1 and 2 as well as SPT reference data. Such event is characterized by a decrease of horizontal magnetic field component $H$, that is $H=\left(X^{2}+Y^{2}\right)^{1 / 2}$, of about $100-200 \mathrm{nT}$ with respect to the initial level of $H$ accompanied by irregular fluctuations of varying frequencies (periods from seconds to hours) and intensities (from nT to tens of nT). The results confirm that MOURA reproduces quite well the magnetic field variations measured by the official SPT magnetometer.

\section{Discussion}

MOURA magnetic instrument is based on an anisotropic magnetoresistive transducer with the purpose of significantly reducing weight in the instrument. Although these transducers do not present optimal magnetic properties and furthermore their response is very temperature dependent, after a careful calibration the instrument presents fairly good performance and fulfils the scientific goal.

In general, the magnetic parameters characterized are in agreement with the manufacturer data sheet. The nonorthogonalities between the in-plane components ( $\mathrm{X}$ and $\mathrm{Y}$ ) are negligible compared to our resolution, and the measured deviation between the $z$ axis and the XY plane is lower than $1^{\circ}$ as specified.
Sensitivities match very well the values of the data sheet, and offsets are lower than the maximum swing specified because the sensors have been screened to choose those with the lowest offsets at room temperature. Regarding the gain drifts with temperature the parameters measured are in accordance with the manufacturer data but there exists a wide dispersion of values as in the gain drift of Sensors 1 and 2 . The observed offset drift with temperature is higher than the values specified by the manufacturer for Set and Reset operation. Also note the anomalous offset drift of the $\mathrm{Z}$ component of Sensor 2. Although the dispersion is attributed to the manufacturing process and is considered normal, it is an important factor, which needs to be taken into account in the selection of components for future missions.

The instrument has been tested in a real environment to measure a geomagnetic storm and the experimental data have been successfully contrasted with those of the reference magnetometer in an official geomagnetic observatory. These measurements demonstrate that the sensor is capable of following dynamically variations of the environmental magnetic field of the order of nT.

\section{Conclusions and future work}

A practical calibration of MOURA magnetometer and gradiometer has been performed to demonstrate its capability to fulfil the pursued scientific objectives on Mars: to measure the magnetic anomalies of the landing site and to observe the daily variation of the field and its perturbations with the solar activity. The calibration comprises the characterization of the offsets, gains, non-orthogonalities and Euler angles, as well as offset and gain drifts with temperature in a range from -60 to $60^{\circ} \mathrm{C}$, and the tilt angle detector characterization. The retrieval software includes the equations to derive 


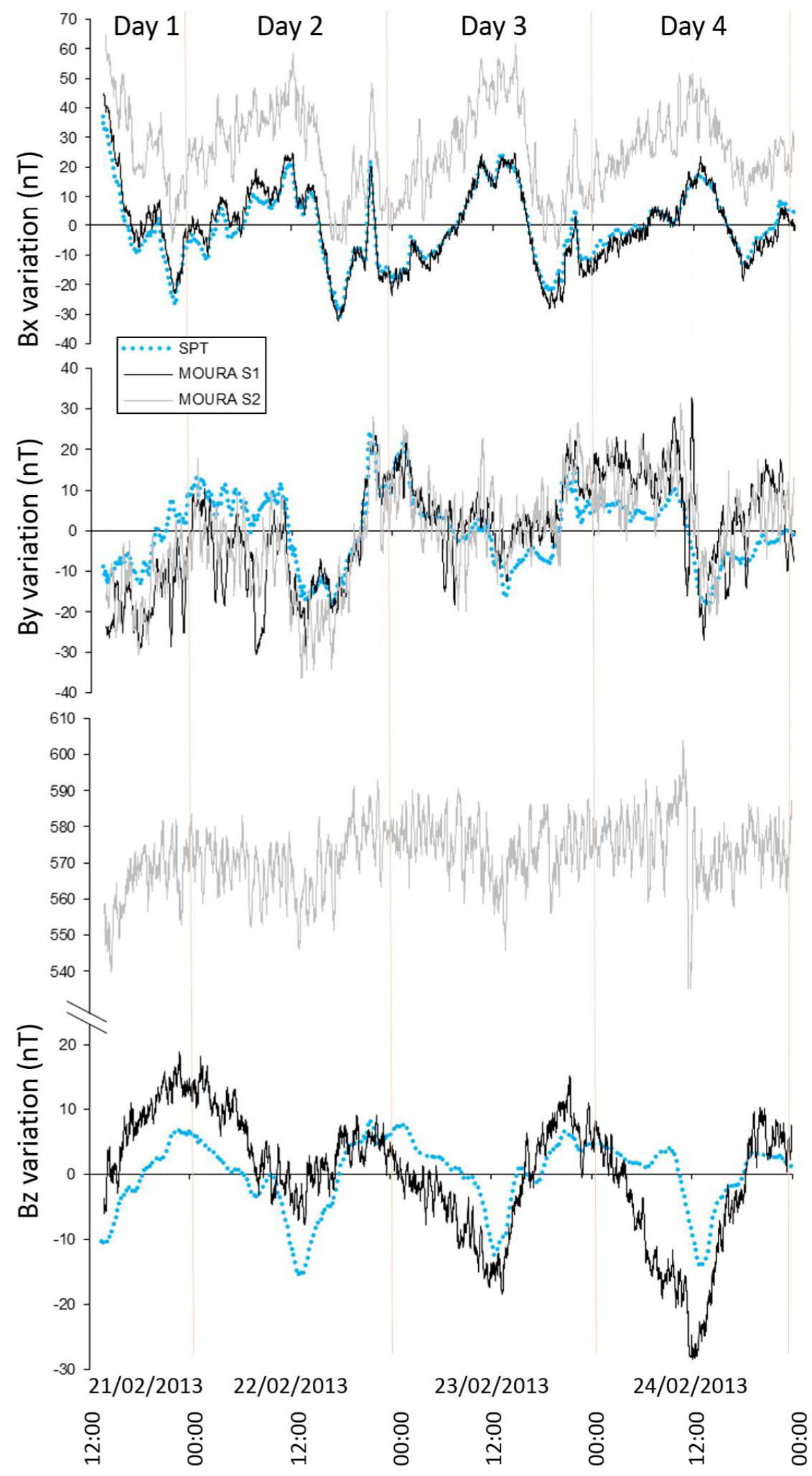

Figure 14. Comparison between measurements from SPT and MOURA, $x$ axis (bottom panel), $y$ axis (middle panel) and $z$ axis (top panel). 


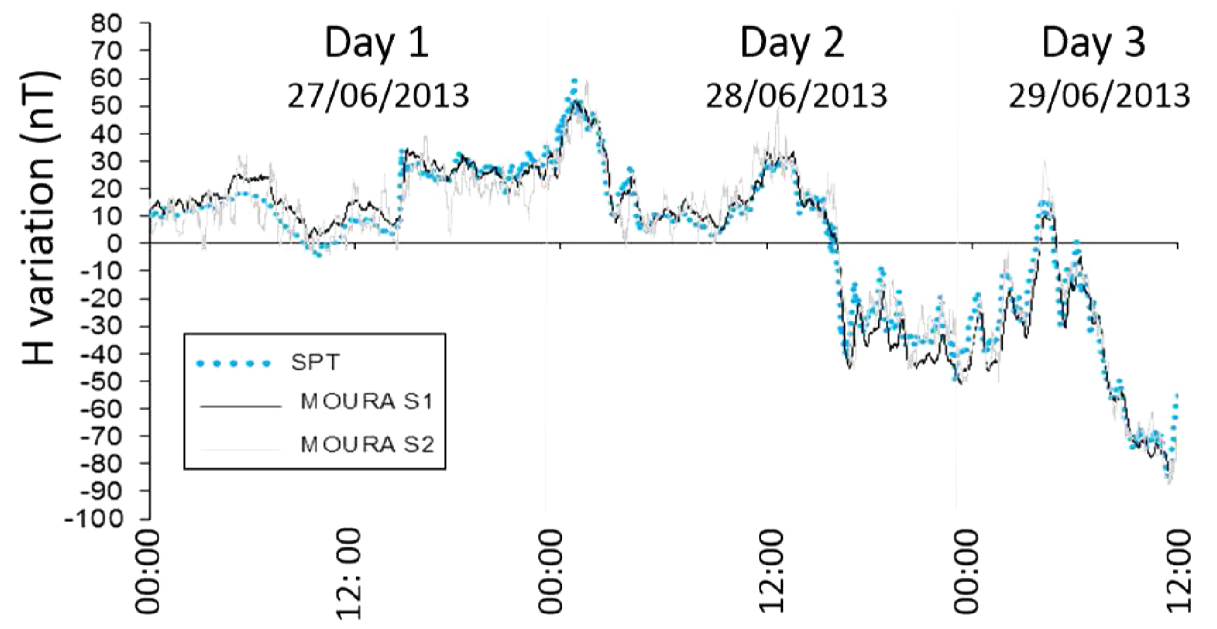

Figure 15. Horizontal component of the geomagnetic field measured with MOURA magnetometer and SPT reference magnetometers on 28-29 June 2013.

the magnetic field referred to the temperature-compensated Martian surface.

The offset drift with temperature has been characterized by means of measurements performed at a reference observatory, San Pablo de los Montes, Toledo.

Finally, a successful comparison of MOURA measurements with the reference magnetometer has been performed during a geomagnetic storm. The results are considered very useful: it is feasible to obtain scientific information on the magnetic environment with a $72 \mathrm{~g}$ compact magnetometer of $<0.5 \mathrm{~W}$. The extended use of such instruments (net of landers/rover) could help the characterization of the unknown Martian magnetic scenario, highly improving the understanding of the remanence of the crust and possibly of the ancient magnetizing field.

In forthcoming works we will also report on our real and long-term prospections with MOURA in comparison with a scalar absolute magnetometer (Geometrics 858), and the data interpretation, to describe the potential of this miniaturized compact magnetometers for rovers and balloons.

Acknowledgements. This work was supported by the Spanish National Space Programme (DGI-MEC) project MEIGA-METNET under the Grant AYA2011-29967-C05-01. The authors wish to thank all the MetNet team for the support, especially Víctor de Manuel and Juan José Jiménez (INTA) and Víctor Apéstigue and Miguel González (ISDEFE), for their technical support, Miguel Ángel Herraiz (UCM) for his help in the discussion of the specifications, and Jose Manuel Tordesillas, Pablo Covisa and José Aguado (SPT) for great support during the campaigns and for allowing the use of the SPT facilities.

Edited by: W. Schmidt

\section{References}

Brown, P., Beek, T., Carr, C., O’Brien, H., Cupido, E., Oddy, T., and Horbury, T. S.: Magnetoresistive magnetometer for space science applications, Measure. Sci. Technol., 23, 025902, doi:10.1088/0957-0233/23/2/025902, 2012.

Cai, J., Andersen, N. L., and Malureanu, C.: In-Field Practical Calibration of Three-Axis Magnetometers, Proceedings of the 2010 International Technical Meeting of the Institute of Navigation, San Diego, CA, 2010.

Diaz Michelena, M., Cobos, P., and Aroca, C.: lock-in amplifiers for AMR sensors, Sensors Actuators A, 222, 149-159, 2015.

D. Michelena, M.: Small Magnetic Sensors for Space Application, Sensors, 4, 2271-2288, 2009.

D. Michelena, M., Arruego, I., Oter, J. M., and Guerrero, H.: COTSBased Wireless Magnetic Sensor for Small Satellites, IEEE T. Aerospace Elect. Syst., 46, 542-557, 2010.

DTUsat: available at: http://www.dtusat.dtu.dk (last access: December 2010), 2014.

Fernández, A. B., Sanz, R., Covisa, P., Tordesillas, J. M., and DíazMichelena, M.: Testing the three axis magnetometer and gradiometer MOURA and data comparison on San Pablo de los Montes Observatory, vol. 15, EGU General Assembly 2013 Conference, Vienna, 2013.

Freitas, P. P., Ferreira, R., Cardoso, S., and Cardoso, F.: Magnetoresistive sensors, J. Phys.-Condens. Mat., 19, 165221 , doi:10.1088/0953-8984/19/16/165221, 2007.

Geomagnetic observatories: available at: www.ign.esandwww. intermagnet.org (last access: October 2013), 2014.

Honeywell Magnetic Sensors: Morristown, NJ, USA, available at: http://www.magneticsensors.com/magnetic-sensor-products. phpHoneywell (last access: October 2013), 2014.

Martínez Catalán, J. R.: The Central Iberian arc, an orocline centered in the Iberian Massif and some implications for the Variscan belt, Int. J. Earth Sci., 101, 1299-1314, 2012.

MMPM - Mars MetNet Mission: available at: http://metnet.fmi.fi (last access: October 2013), 2014. 
Petrucha, V. and Kaspar, P.: 'Calibration of a Triaxial Fluxgate Magnetometer and Accelerometer with an Automated Nonmagnetic Calibration System, 2009 IEEE Sensors Conference, Christchurch, New Zealand, 1510-1513, 2009.

Petrucha, V., Kaspar, P., Ripka, P., and Merayo, J.: Automated System for the Calibration of Magnetometers, J. Appl. Phys., 105, 07E704-1-07E704-3, 2009.

Renaudin, V., Afzal, M. H., and Lachapelle, G.: Complete Triaxis Magnetometer Calibration in the Magnetic Domain, J. Sensors, 2010, 967245, doi:10.1155/2010/967245, 2010.

Ripka, P., Butta, M., and Platil, A: Temperature Stability of AMR Sensors, Sensor Lett., 11, 74-77, 2013.
Sanz, R., Cerdán, M. F., Wise, A., McHenry, M. E., and Díaz Michelena, M.: Temperature dependent Magnetization and Remanent Magnetization in Pseudo-binary $x$ $\left(\mathrm{Fe}_{2} \mathrm{TiO}_{4}\right)-(1-x)\left(\mathrm{Fe}_{3} \mathrm{O}_{4}\right)(0.30<x<1.00) \quad$ Titanomagnetites, IEEE T. Magnet., 47, 4128-4131, 2011.

Sanz, R., Fernández, A. B., Dominguez, J. A., Martín, B., and D. Michelena, M.: Gamma Irradiation of Magnetoresistive Sensors for Planetary Exploration; Sensors, 12, 4447-4465, 2012.

Sordo-Ibáñez, S., Piñero-García, B., Muñoz-Díaz, M., RagelMorales, A., Ceballos-Cáceres, J., Carranza-González, L., Espejo-Meana, S., Arias-Drake, A., Ramos-Martos, J., MoraGutiérrez, J. M., and Lagos-Florido, M. A.: A Front-End ASIC for a 3D Magnetometer for Space Applications Based on Anisotropic Magnetoresistors, Conference Paper, European Conference on Magnetic Sensors and Actuators EMSA, 2014. 